\title{
Kaiserprophetien und Hochverrat. Apokalyptische Schriften und Kaiservaticinien als Medium antikaiserlicher Propaganda
}

\author{
Wolfram Brandes
}

Im Juli oder August des Jahres 1280 erließ Kaiser Michael VIII. Palaiologos ( $\dagger$ 11.12. 1282) ${ }^{1}$ ein Gesetz, das auf den ersten Blick etwas eigenartig anmutet. ${ }^{2}$ Der eigentliche Text dieses Gesetzes ist nicht überliefert. Allein der Historiker Georgios Pachymeres berichtet über den Vorgang; seine Mitteilung darüber und insbesondere der Kontext der Ereignisse sind allerdings schwer zu verstehen. Schon Karl Krumbacher kennzeichnete die Lektüre dieses Geschichtswerkes völlig berechtigt - als "qualvoll“, Nachricht über das Gesetz endet, gehört zu den schwierigsten. Es ging jedenfalls um bestimmte „Flugblätter“ ( $(\alpha ́ \mu \sigma v \sigma \alpha),{ }^{4}$ deren Besitz, Lektüre oder gar Ver-

1 Zu ihm siehe A.M. Talbot, in: ODB 1365; D.M. Nicol, The Last Centuries of Byzantium, 1261 - 1453. Cambridge ${ }^{2}$ 1993, bes. 39-89; D. Geanakoplos, Emperor Michael Palaiologus and the West, 1258-1282. Cambridge 1959; J.-L. van Dieten, in: LexMa VI (1993) 599-600 (hier ist das Todesdatum zu korrigieren); PLP 21528.

2 F. Dölger/P. Wirth, Regesten der Kaiserurkunden des Oströmischen Reiches, Teil III. München ${ }^{2} 1977$, Nr. 2047 (S. 137); der Text des Georgios Pachymeres unten in

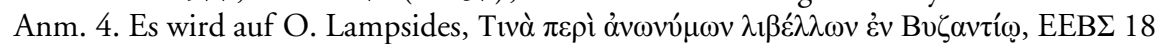
(1948) 144-152, bes. 152, verwiesen, der zwar ausführlich die phamousa behandelt, die basilographeia hingegen nur en passant erwähnt.

3 K. Krumbacher, Geschichte der byzantinischen Litteratur von Justinian bis zum Ende des oströmischen Reiches (565-1453). München ${ }^{2} 1897,288$; vgl. auch H. Hunger, Die hochsprachliche profane Literatur der Byzantiner, I. München 1978, 447-453.

4 Georges Pachymérès, Relations historiques, II (Livres IV-VI). Édition et notes par A. Failler, traduction française par V. Laurent (CFHB 24/2). Paris 1984, 619,29-

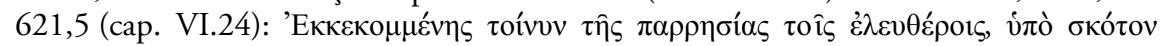

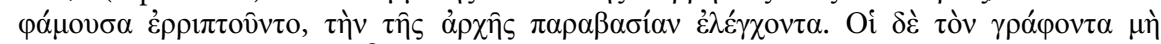

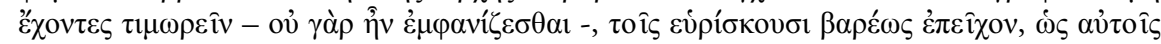

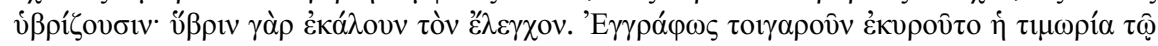

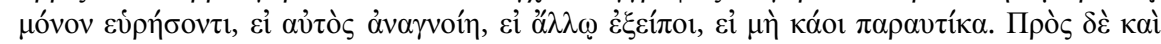

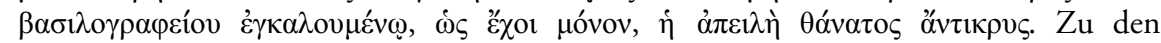

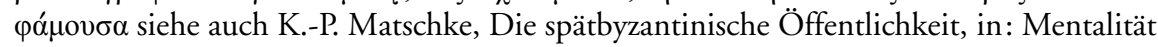
und Gesellschaft im Mittelalter. Gedenkschrift für Ernst Werner, hg. von S. Tanz (Bei- 
breitung unter Strafe gestellt wird. Selbst derjenige, der diese Schriften nicht sofort verbrennt, wird von der Strafe getroffen; den Verfassern wird sogar die Todesstrafe angedroht.

Die „Regesten der Kaiserurkunden des oströmischen Reiches“ von Franz Dölger - bzw. deren Überarbeitung durch Peter Wirth -, wo das Gesetz Kaiser Michaels natürlich erwähnt wird, vermeiden es aus nicht nachvollziehbaren Gründen, den von Pachymeres benutzten Begriff $\beta \alpha \sigma i \lambda \varepsilon$ เo $\rho \alpha \varphi \varphi$ îov anzuführen, mit dem gerade die Sorte von $\varphi \alpha ́ \mu o v \sigma \alpha$ (wie richtig von Dölger/Wirth benannt) bezeichnet wird, deren Verfasser mit dem Tode bedroht werden. Basileiographeion ist eine nicht sehr gebräuchliche, aber doch hinreichend belegte Bezeichnung für eine bestimmte Art kaiserkritischer Schriften. Wir werden uns gleich näher mit ihr zu befassen haben. ${ }^{5}$

Doch zunächst zu den $\varphi \alpha ́ \mu o v \sigma \alpha$ (phamousa): Es handelt sich um ein seit der späteren Spätantike ${ }^{6}$ ins Griechische eingedrungenes lateinisches Fremdwort ( $\varphi \mu \omega \hat{\omega} \sigma o v$ bzw. $\varphi \alpha ́ \mu о v \sigma o v$, vgl. libellus famosus, famosa cartha, carthula famosa, scriptio famosa libellorum, famosus usw.). ${ }^{7}$

Dieses Gesetz Michaels VIII. aus dem Jahre 1280 basiert auf älteren ähnlichen Bestimmungen. Titel 34 des 9. Buchs des Codex Theodosianus, das „ehrabschneidende Schriften“ (De famosis libellis) ${ }^{8}$ behandelt, enthält 10 einschlägige Gesetze von Konstantin dem Großen bis Theodosius II. Die libelli famosi wurden verboten, insbesondere dann, wenn sie anonym waren. Ihre Herstellung und Verbreitung wird als Kapitaldelikt eingestuft. ${ }^{9}$ Ein Gesetz des Kaisers Valens fand darüber hinaus Aufnahme in den Codex Iustinianus. Es ist vermutlich in einem Zusammenhang mit den Exzessen zu sehen, die dieser Kaiser in Szene setzte bzw. setzen ließ und die zu umfassenden Majestäts- und

träge zur Mentalitätsgeschichte, 2). Frankfurt usw. 1993, 155-223, hier 189 f.; J. Dräseke, Byzantinische Hadesfahrten, Neue Jahrbücher für das klassische Altertum 15 (1912) 343-366, sah in Mazaris' Hadesfahrt ein derartiges pónovбov. Aber der Begriff der Satire ist wohl angebrachter.

$5 \mathrm{Zu} \beta \alpha \sigma i \lambda \varepsilon 10 \gamma \rho \alpha \varphi \varepsilon i ̂$ v siehe ausführlich unten S. 161-172.

6 Diese Bezeichnung wird hier im Sinne von W. Liebeschütz, Late Late Antiquity $\left(6^{\text {th }}\right.$ and $7^{\text {th }}$ centuries) in the Cities of the Roman Near East, Mediterraneo Antico 3 (2000) 4375, verwendet.

7 Vgl. die Nachweise bei Lampsides, EEB 18 (1948) 145 (aus dem Codex Theodosianus); E.A. Sophocles, Greek Lexicon of the Roman and Byzantine Periods. Cambridge, Mass./Leipzig 1914 (Nachdruck Hildesheim usw. 1992), 1134 (s.v. $\varphi \alpha \mu \omega \hat{\sigma o v}$ ); C. Du Fresne S. du Cange, Glossarium ad scriptores mediae et infimae Graecitatis, I-II. Lyon 1688 (Nachdruck Graz 195), 1663 (s.v. pó $\mu \omega \sigma \sigma o v, ~ \varphi \alpha ́ \mu o v \sigma o v)$.

8 Zur Bedeutung in den lateinischen Rechtsquellen siehe z. B. H. Heumann/E. Seckel, Handlexikon zu den Quellen des römischen Rechts. Graz ${ }^{10} 1958$, 209: „die Ehre jemandes angreifend, ehrenrührig“.

9 Siehe Th. Mommsen, Römisches Strafrecht. Leipzig 1899, 565, 794; E. Polay, Iniuria Types in Roman Law. Budapest 1986, 150, 172 f., 176 f., 189 f. 
Magieprozessen führten. ${ }^{10}$ Ammianus Marcellinus berichtet in aller Ausführlichkeit über die Vorgänge, ${ }^{11}$ die mutatis mutandis zahlreiche Parallelen zu den Verfolgungen Michaels VIII. am Ende des 13. Jhs. aufweisen.

Diese einschlägigen Gesetze kannte man natürlich auch in späteren Jahr-

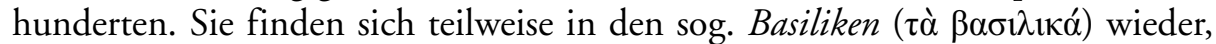
der großen Gesetzeskompilation des Makedonenkaisers Basileios I. bzw. seines Sohnes Leon VI. aus dem Jahre 888. ${ }^{12}$ Der große Kanonist Theodoros Balsamon zitiert sie nach den Basiliken in seinem Kommentar zum Nomokanon in XIV Titeln (Ende 12. Jh.). ${ }^{13}$ Auch der Historiker und Jurist Michael Attaleiates im 11. Jh., ${ }^{14}$ um ein weiteres Beispiel zu nennen, widmet in seinem "Geset-

10 E. Stein, Vom römischen zum byzantinischen Staate (284-476 n. Chr.). Wien 1928, 273; O. Seeck, Geschichte des Untergangs der antiken Welt, V. Stuttgart ${ }^{4} 1921$ (Nachdruck Darmstadt 2000), 10 und die Anm. auf S. 425; F. Zuccotti, „Furor Haereticorum". Studi sul trattamento giuridico della folia e sulla persecuzione della eteredossia religiosa nella legislazione del tardo imperio. Milano 1992; N. Zeddies, Religio et sacrilegium. Studien zur Inkriminierung von Magie, Häresie und Heidentum (4.7. Jahrhundert). Frankfurt usw. 2003, passim (umfassende Bibliographie); H. Funke, Majestäts-und Magieprozesse bei Ammianus Marcellinus, JbAC 10 (1967) 145-175; M.Th. Fögen, Die Enteignung der Wahrsager. Studien zum kaiserlichen Wissensmonopol in der Spätantike. Frankfurt am Main 1993; U. Riedinger, Die Heilige Schrift im Kampf der griechischen Kirche gegen die Astrologie. Innsbruck 1956; H.J. Magoulias, The Lives of Byzantine Saints as Sources of Data for the History of Magic in the Sixth and Seventh Centuries A.D.: Sorcery, Relics and Icons, Byz 37 (1967) 259-269.

11 Ammianus Marcellinus, Römische Geschichte. Lateinisch und deutsch und mit einem Kommentar versehen von W. Seyfarth, IV (Schriften und Quellen der Alten Welt, 21/4). Berlin 1971, 146-167 (29,1,5-2,28).

12 Siehe CTh 9.34,1-10 (De famosis libellis) - von 319 bis 406; C. 9.36 (а. 365); B.

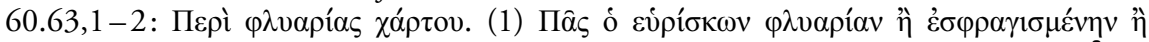

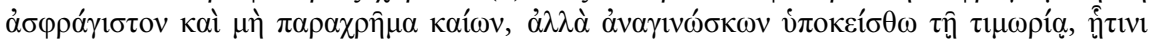

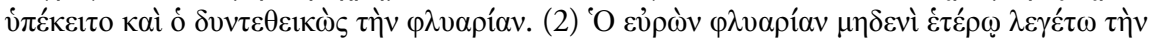

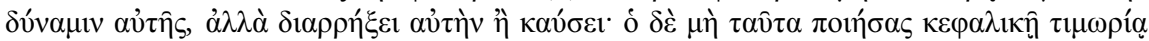

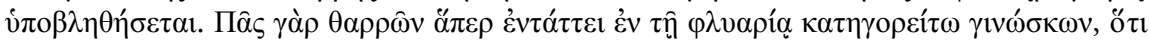

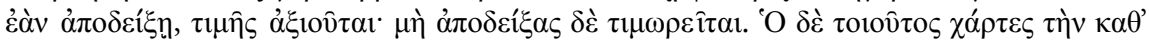

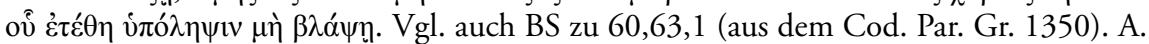
Schminck, ,Frömmigkeit ziere das Werk'. Zur Datierung der 60 Bücher Leons VI., Subseciva Groningana 3 (1989) 79-114, zeigt, daß die Basiliken im Jahre 888 pro-

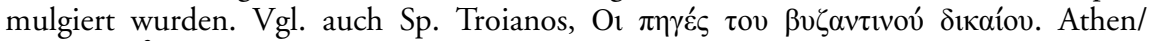
Komotini ${ }^{2} 1999,181-189$.

$13 \mathrm{Zu}$ Balsamon siehe A. Kazhdan, ODB 249; V. Tiftixoglu, Zur Genese der Kommentare des Theodoros Balsamon, in: Byzantium in the $12^{\text {th }}$ Century. Canon Law, State and Society, ed. by N. Oikonomides. Athen 1991, 483-532; Troianos, Or $\pi \eta \gamma \varepsilon \dot{s}$ (wie

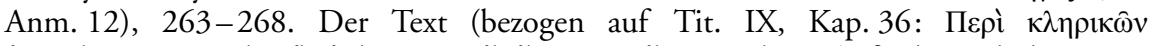

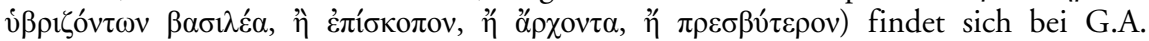

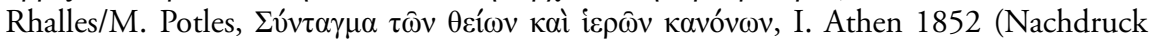
Athen 1866), 229,5-14. Er zitiert B. 60.63,1-2.

14 A. Kazhdan, ODB 229; siehe demnächst eine Monographie von Ruth Macrides über Attaleiates. 
zeswerk“ (Поí $\mu \alpha$ vo vıкóv) den „Pamphleten der Geschwätzigkeit/üblen

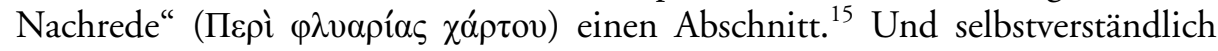
sind diese Bestimmungen auch in der Synopsis maior der Basiliken (aus dem 10. Jh.) enthalten. ${ }^{16}$

Ein weiterer Aspekt ist jedoch noch zu beachten. Diese Pamphlete, zumindest dann, wenn sie in Verbindung zum Kaiser gebracht wurden, konnten als crimen laesae maiestatis, als Hochverrat $(\kappa \alpha \theta 0 \sigma i ́ \omega \sigma i \varsigma){ }^{17}$ gewertet werden. ${ }^{18} \mathrm{Im}$ justinianischen Recht ist das Delikt des Hochverrats in C.9.8.1-6 (Ad legem Iuliam maiestatis) geregelt. Die dort gesammelten Gesetze bedrohen den des Hochverrats Überführten mit Todesstrafe und Konfiskation des Vermögens. Die Folter ist zugelassen. In gewissem Sinne ist auch C.9.7.1 (Si quis imperatori maledixerit) relevant, zumal dieses Gesetz sich auch in den Basiliken wiederfindet. Es besagt, daß Fälle von Hochverrat vom Kaiser entschieden werden. ${ }^{19}$ Der Procheiros Nomos aus dem ausgehenden 9. $\mathrm{Jh}^{20}$ verfügte in eindeutiger Weise: „Wer gegen das Heil des Kaisers agitiert, verfällt dem Tode und der Konfiskation des Vermögens. “21 Michaels VIII. Gesetz und die Verfolgungen,

15 Michaelis Attaliotae Пoí $\mu \alpha$ vouıкóv, in: J. und P. Zepos, Ius Graeco-Romanum, VII. Athen 1931, 487 f.; entspricht C. 9,36,2 bzw. B. 60,63,2. Zu Attaleiates siehe Troianos,

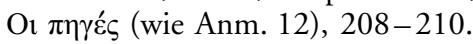

16 Synopsis maior Basilicorum, in: Zepos, Ius Graeco-Romanum (wie Anm. 15), V, 567 (Ф. $\mathrm{IV}, 1)=$ B. 60,63,1-2. Zur Synopsis maior siehe L. Burgmann, ODB 1995; N.G. Svoronos, La synopsis major des Basiliques. Paris 1964.

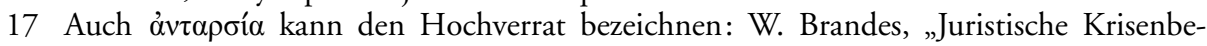
wältigung“ im 7. Jahrhundert? Die Prozesse gegen Martin I. und Maximos Homologetes, Fontes Minores X (1998) 141-212, hier $163 \mathrm{f}$., doch entspricht dies einem eher untechnischen Sprachgebrauch.

18 K.E. Zachariae von Lingenthal, Geschichte des griechisch-römischen Rechts. Aalen ${ }^{3}$ 1955, 336 f.; A. Kazhdan, ODB 2110 f.; B. Kübler, RE 14 (1930) 544-559; Sp.

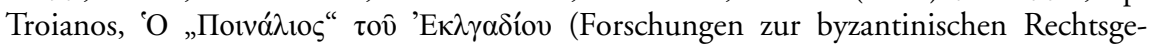

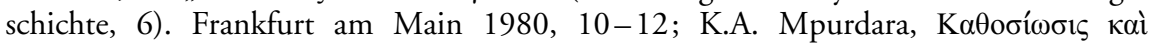

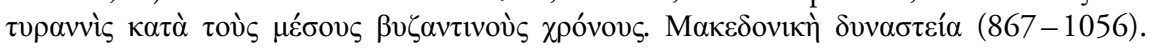
Athen 1981; C.H. Brecht, Perduellio und crimen maiestatis, ZRG rom. Abt. 64 (1944) $345-359$.

19 B. 60.36 .13 sowie 10.32 .44 .

20 Vgl. A. Schminck, ODB 1725; Ders., Studien zu mittelbyzantinischen Rechtsbüchern (Forschungen zur byzantinischen Rechtsgeschichte, 13). Frankfurt am Main 1986, 62 ff.;

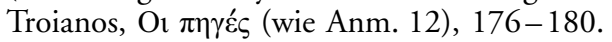

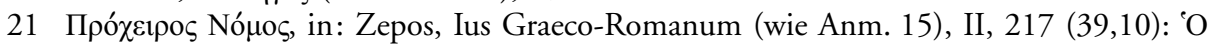

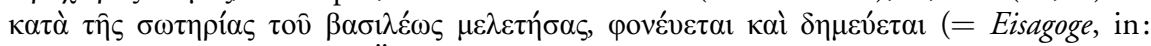
Zepos a.a.O. $361[40,12])$. Übersetzung nach Zachariae von Lingenthal, Geschichte des griechisch-römischen Rechts (wie Anm. 18), 337; siehe auch Konstantin Harmenopulos, Manuale legum sive Hexabiblos, ed. G.E. Heimbach. Leipzig 1851 (Nachdruck Aalen 1969), $772(6,14,2)$. 
die mit ihm im Zusammenhang standen, ${ }^{22}$ blieben grundsätzlich im Rahmen des überlieferten Rechts.

Es ist davon auszugehen, daß Michaels VIII. Verbot der $\varphi \alpha ́ \mu o v \sigma \alpha$ mithin keine Neuerung darstellte, sondern jahrhundertealte Bestimmungen aufnahm und konkretisierte. Es gab zu allen Zeiten Pamphlete, die - aus welchen Gründen auch immer - in Umlauf gebracht wurden. Auch Kritik am Kaiser und an politischen (besonders an kirchenpolitischen) Entscheidungen gab es stets. ${ }^{23} \mathrm{Da}$ die byzantinische Bevölkerung einen ausreichend hohen Alphabetisierungsgrad aufwies, was in erster Linie für die Hauptstadt Konstantinopel und einige andere städtische Zentren wie Thessaloniki gilt, erregten solche „Flugblätter“ einiges Aufsehen, und ihre gefährliche Wirkung wurde entsprechend auch vom Staat als hoch eingestuft und bekämpft. Das erklärt die erwähnten Gesetze.

Neu an dem Gesetz Michaels VIII. ist allein das Verbot der Schriften, die

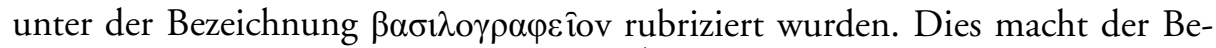
richt des Georgios Pachymeres deutlich. ${ }^{24}$

Es wird hier erkennbar, daß es gerade der Begriff des $\beta \alpha \sigma \iota \lambda$ o $\rho \alpha \varphi \varepsilon$ îov ist, der von besonderer Bedeutung war. Das neue „Lexikon zur byzantinischen Gräzität“ übersetzt $\beta \alpha \sigma \iota \lambda o \gamma \rho \alpha \varphi \varepsilon \hat{i o v}$ mit ,antikaiserliche Schrift “ ${ }^{25}$ Dies ist sicher zutreffend, doch läßt sich der Begriff noch näher spezifizieren. Bereits Du Cange verwies in seinem "Glossarium“ auf eine Literaturgattung, die mit diesem Begriff in Verbindung gebracht werden kann. ${ }^{26}$ „Eine possenhafte Schrift, B $\alpha$ -

22 Dazu ausführlicher unten S. 179-181.

23 Siehe den oben in Anm. 4 zitierten Aufsatz von Matschke sowie Lampsides, EEB 18 (1948).

24 Georges Pachymérès, Relations historiques, II, ed. Failler (wie Anm. 4), 621,4 f.: Прò $\delta \grave{\varepsilon}$

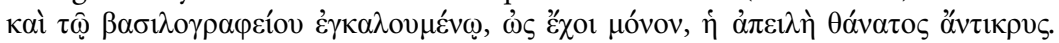

25 E. Trapp, Lexikon zur byzantinischen Gräzität besonders des 9.-12. Jahrhunderts, I.

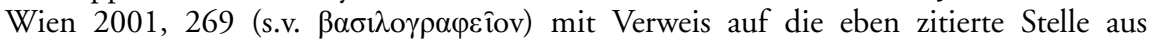
Pachymeres. Vgl. schon Pierre Poussines, den Ersteditor des Geschichtswerks des Georgios Pachymeres (Rom 1666/1669), der in seinem Glossarium (abgedruckt in: Georgii Pachymeris de Michaele et Andronici Palaeologis libri XIII, rec. I. Bekker, I. Bonn 1835, 535-621, hier 549) schrieb: „unde intelligendum crimen libelli contra imperatorem scripti lecti habiti peculiari vocabulo $\beta \alpha \sigma \lambda \lambda \varepsilon$ เo $\rho \rho \varphi \varphi \varepsilon \hat{\imath o v}$ fuisse vocatum, et ei mortis poenam constitutam."

26 Siehe Du Cange, Glossarium (wie Anm. 7), 181 (mit Verweis auf Pachym. VI,24), sowie

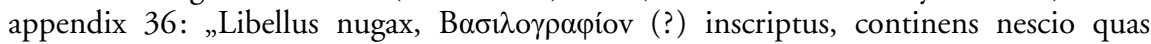
Prophetias de Imperatoribus, cujusmodi sunt illae, quae Danielis nomen praeferebant."; Mittellateinisches Wörterbuch I. München 1967, 1387 (s.v. basilographia); D. Deme-

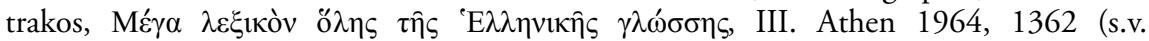

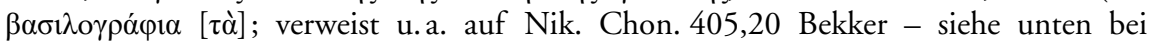


$\sigma i \lambda o \gamma \rho \alpha \varphi$ ó (?) tituliert, die, ich weiß nicht welche, Weissagungen über Kaiser enthält, von der Art, die den Namen Daniels tragen“. Der große französische Gelehrte sah also einen Zusammenhang mit den byzantinischen Daniel-Apokalypsen, von denen eine erhebliche Anzahl erhalten blieb. ${ }^{27}$ Leider hat sich in das sonst so zuverlässige Wörterbuch von Du Cange offensichtlich ein Druckfehler eingeschlichen: ${ }^{28}$ Der von ihm als Beleg angeführte "Cod. Reg. 2980“29 (neben der hier behandelt Stelle bei Georgios Pachymeres) bietet nämlich den Begriff $\beta \alpha \sigma i \lambda \varepsilon$ co $\rho \alpha \varphi \varepsilon$ iov nicht. ${ }^{30}$ Pertusi meinte deshalb, daß es sich um den Codex Parisinus Graecus 2180 gehandelt haben müsse. Dieser enthält zwar eine

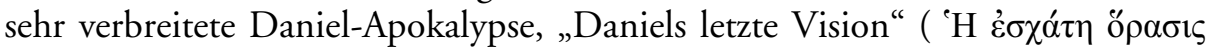

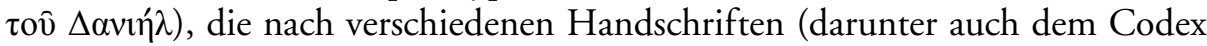
Parisinus graecus 2180) ediert wurde, ${ }^{31}$ doch läßt sich weder den Editionen dieses Textes noch den einschlägigen Beschreibungen der Handschrift entneh-

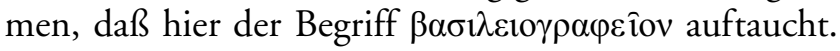

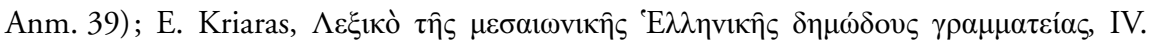
Thessalonike 1975, 60 (Verweis auf die mittelgriechische Alexanderdichtung und die vulgärsprachige Niketasparaphrase - siehe unten bei Anm. 39 sowie 46-50).

27 Siehe die Übersicht bei W. Brandes, Die apokalyptische Literatur, in: Quellen zur Geschichte des frühen Byzanz (4.-9. Jahrhundert). Bestand und Probleme, hg. von F. Winkelmann/W. Brandes (BBA 56), Berlin 1990, 305-322, 367-370, hier bes. 317319; nur ein Teil der relevanten Texte ist bei P.J. Alexander, The Byzantine Apocalyptic Tradition, ed. with an introduction by D. de F. Abrahamse. Berkeley/Los Angeles/ London 1985, behandelt; siehe auch die Übersicht bei A. Pertusi, Fine di Bisanzio e fine del mondo. Significat e ruolo storico delle profezie sulla caduta di Costantinopoli in Oriente e in Occidente (Nouvi studi storici, 3). Roma 1988, 35-128. Auch Pertusi behandelt nicht alle relevanten Texte. Man darf allerdings nicht vergessen, daß Alexander und Pertusi starben, bevor sie ihre Monographien zur byzantinischen Apokalyptik be-

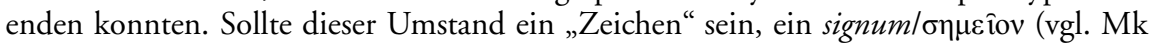
13,4 und Lk 21,7), das vor der Beschäftigung mit dieser Materie warnt?

28 Pertusi, Fine di Bisanzio (wie Anm. 27), 68 mit Anm. 196. Bereits 1874 hatte dies aber schon Legrand (wie Anm. 32) bemerkt, was Pertusi entgangen ist.

29 Du Cange, Glossarium (wie Anm. 7), 36 (appendix).

30 Vgl. H. Omont, Inventaire sommaire des manuscrits grecs de la Bibliothèque Nationale, III. Paris 1888 (Nachdruck Hildesheim/Zürich/New York 2000), 78; P. Boudreaux, CCAG VIII/4, 73 (Nr. 94).

31 E. Klostermann, Analecta zur Septuaginta, Hexapla und Patristik. Leipzig 1895, 115120 (dazu Ders., ZNW 15 [1895] 147-150); H. Schmoldt, Die Schrift „Vom jungen Daniel“ und „Daniels letzte Vision“. Herausgabe und Interpretation zweier apokalyptischer Texte. Diss. theol. Hamburg 1972, 122-144; A. Vassiliev, Anecdota GraecoByzantina, I. Moskau 1893, 43-47; V. Istrin, Otkrovenie Mefodija Patarskago i apokrifičeskija videnija Daniila v vizantijskoj i slavjano-russkoj literaturach. Moskva 1897, 135-139; C. von Tischendorf, Apocalypses apocryphae. Leipzig 1866, XXX-XXXIII (Auszüge). Zu den byzantinischen Danielapokalypsen siehe jetzt L. DiTommaso, The Book of Daniel and the Apocryphal Daniel Literature (Studia in Veteris Testamenti Pseudepigrapha, 20). Leiden/Boston 2005, passim. 
Bereits vor langer Zeit (1874) vermutete hingegen Legrand, ${ }^{32}$ daß es sich um den Codex Parisinus Graecus 426 (a. 1488) gehandelt habe. ${ }^{33}$ Diese Handschrift wurde von Du Cange bei der Arbeit an seinem Lexikon intensiv benutzt, wie die häufigen Verweise auf sie verdeutlichen. Der Codex enthält u.a. die vulgär-

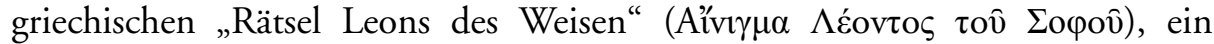
Derivat der verbreiteten Orakel, die demselben Kaiser zugeschrieben wurden, ${ }^{34}$ sowie eine weitere, sehr verbreitete, Weissagung über das Schicksal von Kon-

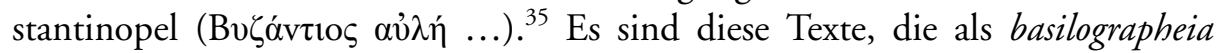

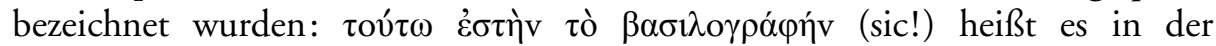
Handschrift. Auch dieser Umstand wird uns noch näher beschäftigen.

Die Belege für $\beta \alpha \sigma i \lambda o \gamma \rho \alpha \varphi \varepsilon i ̂ o v$ lassen sich weiter vermehren. Es wird deutlich, daß die eingangs erwähnte Stelle bei Georgios Pachymeres nicht so isoliert dasteht, wie man angesichts der bisherigen Untersuchungen vermuten könnte.

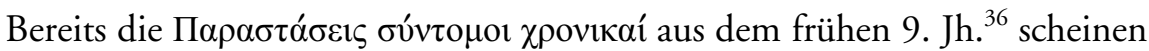
einen Hinweis auf derartige Schriften zu enthalten. Es ist an einer Stelle die

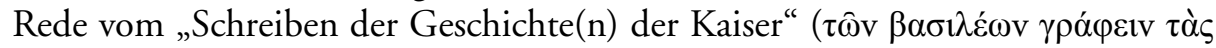

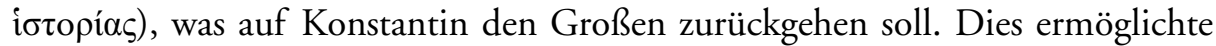
angeblich die Deutungen der beiden Gorgonenhäupter, die man noch heute in der Yerebatan-Zisterne bewundern kann. ${ }^{37}$ Auch dieser Kontext deutet also auf die byzantinische Weissagungsliteratur.

32 Ch. Gidel/É. Legrand, Les oracles de l'empereur Léon le Sage, Annuaire de l'Association pour l'encouragement des études grecques en France 8 (1874) 150-192, hier 159.

33 Vgl. H. Omont, Inventaire sommaire des manuscrits grecs de la Bibliothèque Nationale I. Paris 1886 (Nachdruck Hildesheim/Zürich/New York 2000), 46.

34 Siehe die Editionen bei Gidel/Legrand (wie Anm. 32) 173-192 (nach dieser Hs.) und E. Trapp, Vulgärorakel aus Wiener Handschriften, in: 'AкроӨ́vio. Sodalium Seminarii Byzantini Herberto Hunger oblata. Wien 1964, 83-120, hier 86-104. Zu diesem Text siehe Mango, ZRVI 6 (1960) $66 \mathrm{f}$.

$35 \mathrm{Zu}$ diesem häufig gedruckten Text siehe unten bei Anm. 73.

36 Th. Preger, Scriptores originum Constantinopolitanarum, I. Leipzig 1901 (Nachdruck Leipzig 1989), 45,15-46,1 (cap. 40); Av. Cameron/J. Herrin, Constantinople in the Early Eighth Century: The Parastaseis syntomoi chronikai (Columbia Studies in the Classical Tradition, 10). Leiden 1984, 108/110 (vgl. auch den Kommentar S. 223); zur Datierung siehe G. Dagron, Constantinople imaginaire. Études sur le recueil des Patria. Paris 1984, 29-48; O. Kresten, Leon III. und die Landmauern von Konstantinopel. Zur

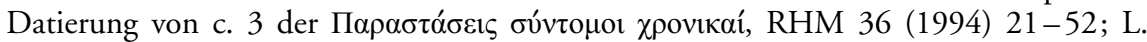
Brubaker/J. Haldon, Byzantium in the Iconoclastic Era (ca 680-850): The Sources (Birmingham Byzantine and Ottoman Monographs, 7). Aldershot 2001, $301 \mathrm{f}$; ; siehe auch A. Kazhdan, ODB 1586 sowie Dens., A History of Byzantine Literature (650850). Athen 1999, 308-313, obwohl seine Ausführungen (u.a. zur Datierung) nicht überzeugen. Ich schließe mich A. Berger, Untersuchungen zu den Patria Konstantinu-

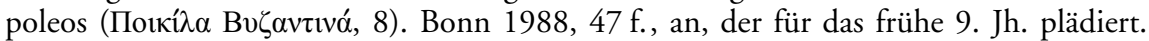

37 Vgl. W. Müller-Wiener, Bildlexikon zur Topographie Istanbuls. Tübingen 1977, 282 f. 
Weitere Belege stammen aus der Zeit nach dem 12./13. Jh. Die volkssprachliche Paraphrase des Geschichtswerkes des Niketas Choniates aus dem Anfang des 14. Jhs. ${ }^{38}$ kennt diesen Begriff, und der Zusammenhang, in dem er auftaucht, ist bezeichnend. Andronikos I. ließ nach der Verhaftung des Alexios Komnenos (unehelicher Sohn Manuels I. und Gatte der Eirene, Tochter Andronikos' I.) auch dessen hypographeus Mamalos festnehmen und bei lebendigem Leibe öffentlich im Hippodrom verbrennen. Zusammen mit Mamalos wurden einige Bücher verbrannt, welche die zukünftigen Kaiser behandelten. Mamalos habe diese Bücher heimlich mit Alexios gelesen und diesen so verleitet, nach der Kaiserherrschaft zu streben. Die Paraphrase des Geschichtswerkes fügt erklärend hinzu, daß es sich um $\beta \alpha \sigma \imath \lambda o \gamma \rho \alpha ́$ cı $\alpha$ handelte. ${ }^{39}$ Auch eine Jerusalemer Handschrift (aus der Bibliothek des dortigen orthodoxen Patriarchats) bezeichnet mit $\beta \alpha \sigma \imath \lambda$ о $\rho \alpha \varphi \varepsilon i ̂$ v die bekannten „Orakel Leons des Weisen“. ${ }^{40}$

Übersehen wurde bisher (unter den relevanten Lexika macht nur Kriaras eine Ausnahme ${ }^{41}$ ), daß das volkssprachige $\beta \alpha \sigma i \lambda o \gamma \rho \alpha ́ \varphi v v$ in der mittelgriechischen Alexanderliteratur auftaucht, einer beliebten Lektüre. Relevant für die vorliegende Untersuchung sind der mittelgriechische Alexanderroman in Prosa ${ }^{42}$

38 So nach John Christian Davis, John V, Anne of Savoy, and an Imperial Training Programme Designed to Preserve a Dynasty (Vortrag auf dem International Medieval Congress, Leeds 12-15 July 2004), mit guten Argumenten für eine Datierung in die Zeit Andronikos' II.

39 Nicetae Choniatae historia, rec. I.A. van Dieten (CFHB 11/1). Berlin/New York 1975,

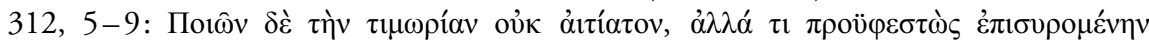

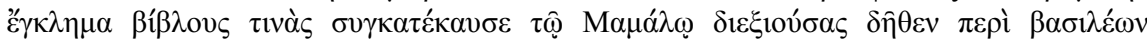

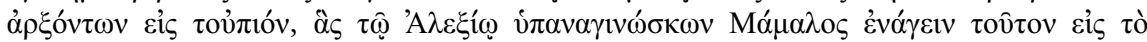

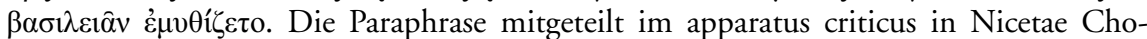

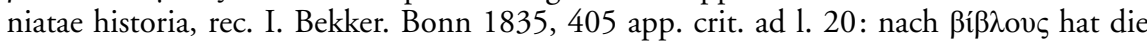

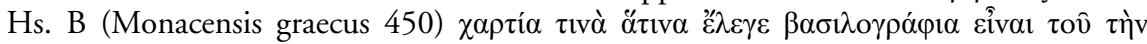

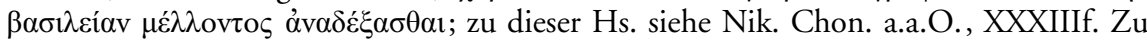

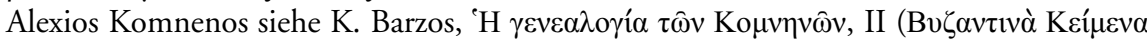

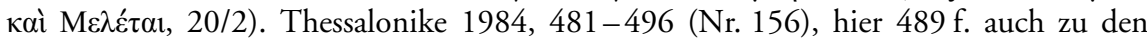
basilographia.

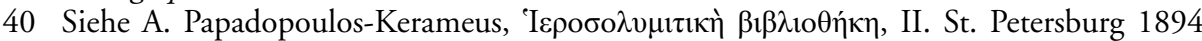

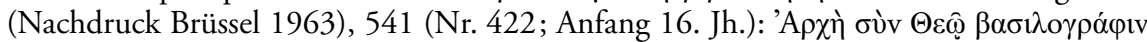

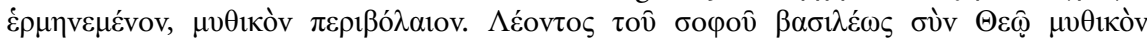

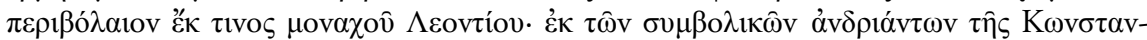

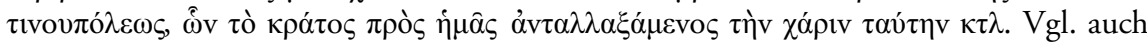

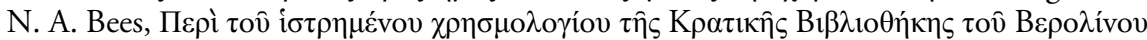

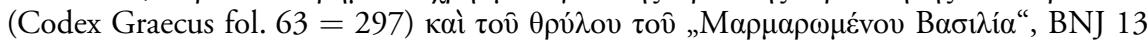

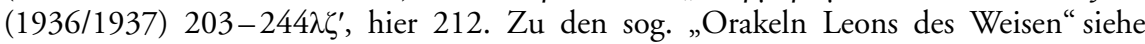
unten S. 169.

41 Kriaras, $\Lambda \varepsilon \xi ı$ кó (wie Anm. 26) IV, 60.

42 J. Trumpf bei R. Merkelbach, Die Quellen des griechischen Alexanderromans (Zetemata 9). München ${ }^{2} 1977,212$ ff.; es gibt noch keine kritische Ausgabe; Übersicht über die Hss. bei U. Moennig, Die spätbyzantinische Rezension *广 des Alexanderromans (Neo- 
und das im 14. Jh. entstandene byzantinische Alexandergedicht. ${ }^{43}$ Bereits die von Moennig rekonstruierte Rezension * $\zeta$ enthielt aller Wahrscheinlichkeit nach die gleich anzuführende Geschichte. ${ }^{44}$ Diese Rezension * ${ }^{*}$ ist zwar bekanntlich nicht direkt griechisch überliefert - sie wurde vermutlich durch spätere Fassungen verdrängt -, doch stellte sie den Ausgangspunkt für die verschiedenen slawischen Übersetzungen des Alexanderromans dar. ${ }^{45}$ Auf deren Basis wurde sie rekonstruiert. Man kann wohl voraussetzen, daß sie seit dem 14. Jh. existierte.

Der Umstand, daß dieser Begriff in der mittelgriechischen Alexanderdichtung auftaucht, ist angesichts der starken Verbreitung dieser Texte ein wichtiges

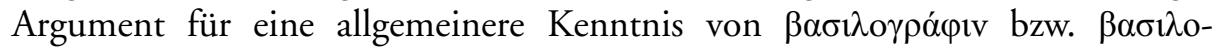

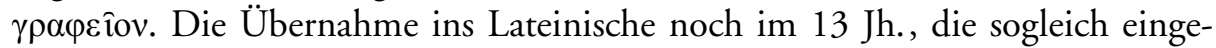
hender zu besprechen sein wird, ${ }^{46}$ ging vermutlich von der Volkssprache aus. Ein Sicard von Cremona und - über welche Vermittlungen auch immer - der Verfasser der Erythräischen Sibylle, der bekannten Weissagungsschrift aus der

graeca medii aevi, 6). Köln 1992, 38-45; J. Trumpf, Zur Überlieferung des mit-

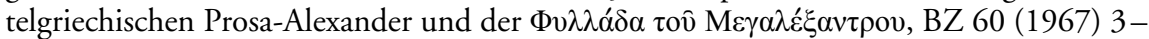
40. Siehe auch (obwohl in Teilen fragwürdig: H. Hunger, JÖBG 17 [1968] 298-300; M. Naoumides, Comparative Literature Studies 6 [1969] 334-337; J. Trumpf, BZ 62 [1969] 79-81; L. Politis, Hell. 23 [1970] 386-396) K. Mitsakis, Der byzantinische Alexanderroman nach dem Codex Vindob. Theol. Gr. 244 (MBM 7). München 1967; A. Lolos/V. Konstantinopulos, Ps.-Kallisthenes: Zwei mittelgriechische Prosa-Fassungen des Alexanderromans, I-II (Beiträge zur klassischen Philologie, 141/150). Königstein i.T. 1983 (ebenfalls heftig kritisiert: H. Tonnet, REG 97 [1984] 576-577; M. van Esbroeck, Les études classiques 53 [1985] 282; A. van Gemert, Anzeiger für die Altertumswissenschaften 40/1-2 [1987] 21-26).

43 Trumpf bei Merkelbach, Die Quellen (wie Anm. 42), 96 f., 212 ff.; Ausgaben: W. Wagner, Trois poèmes grecs du moyen-age. Berlin 1881; S. Reichmann, Das byzantinische Alexandergedicht nach dem Codex Marcianus 408 (Beiträge zur klassischen Philologie, 13). Meisenheim am Glan 1963.

44 Moennig, Rezension * (wie Anm. 42), 115 f., 120 und bes. 192 f. Moennig selbst bezeichnet in vorsichtiger Weise die Rezension * ${ }^{*}$ als „Konstrukt“ (a.a.O. 38), doch ändert das nichts an seinen überzeugenden Ergebnissen.

45 Siehe R. Marinković/V. Jerković, Srpska Aleksandrida, II. Belgrad 1985; J. Kristophson, Der mittelgriechische und der serbische Prosaalexander, Folia Neoellenica 7 (1985/1986) 33-61; St. Novaković, Pripovetka o Aleksandru Velikom u staroj srpskoj književnosti. Kritički tekst i rasprave. Belgrad 1878; D. Christians, Der Besuch Alexanders des Großen bei den Gymnosophisten aus dem südslawischen Alexanderroman nach der Handschrift Nr. 771 der Nationalbibliothek Sophia (Bausteine zur Geschichte der Literatur bei den Slawen, 33). Köln/Wien 1988; Ders., Die serbische Alexandreis nach der Sofioter illustrierten Handschrift Nr. 771 (Bausteine zur slavischen Philologie und Kulturgeschichte. Reihe B: Editionen, Neue Folge 2). Köln 1991; I. Köhler, Der neubulgarische Alexanderroman. Untersuchungen zur Textgeschichte und Verbreitung. Phil. Diss. Hamburg 1973; F.P. Magoun, Stojan Novaković on the So-Called ,Serbian Alexander', Byz 16 (1942/1943) 315-338; siehe auch die Übersicht über die Ausgaben und die wichtigsten Handschriften bei Moennig, Rezension *广 (wie Anm. 42), 38-40. Dazu gleich S. $168-170$. 
Mitte des 13. Jhs., hatten sicher eher Kontakt mit Griechen, welche die Volkssprache benutzten, als mit Gelehrten in Byzanz, die sich einer „reineren“ Sprache bedienten. ${ }^{47}$

Was aber noch wichtiger ist: Im mittelgriechischen Alexanderroman wird

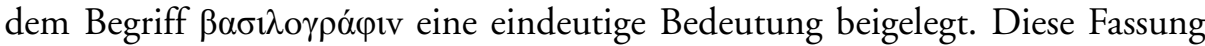
basiert weitgehend auf der sog. $\varepsilon$-Rezension (hg. von Trumpf) aus dem 8. Jh. (oder doch später?), schmückt diese jedoch an zahlreichen Stellen auf höchst phantastische Weise aus. Die $\varepsilon$-Rezension bietet nur einen kurzen Bericht über einen Zug Alexanders gen Westen, gegen Rom, das sich umgehend unterwarf. ${ }^{48}$

Anders im mittelgriechischen Prosa-Alexander. Hier wird ausführlich dargestellt, wie Alexander, reich beschenkt, auf Bukephalos in Rom einzog und sich selbst die Krone der Kleopatra aufs Haupt setzte. Man führte ihn zum Tempel des Apollon, und die Priester gaben ihm eine Schriftrolle in die Hand, Ěva $\chi \alpha$ ó $\tau$. Deren Inhalt läßt sich leicht zusammenfassen. Es handelt sich um eine nicht ungeschickt komprimierte Wiedergabe von Dan. 8,3-11 („... und ich sah, ..., ein Widder stand vor dem Wasser, der hatte zwei hohe Hörner, doch eines höher denn das andere, und das höchste wuchs am letzten. [4] Ich sah, daß der Widder mit den Hörnern stieß gegen Abend, gegen Mitternacht und gegen Mittag; und kein Tier konnte vor ihm bestehen, noch von seiner Hand errettet werden, sondern er tat, was er wollte, und ward groß. [5] Und indem ich darauf merkte, siehe, so kommt ein Ziegenbock vom Abend her über die ganze Erde, daß er die Erde nicht rührte; und der Bock hatte ein ansehnlich Horn zwischen seinen Augen. [6] Und er kam bis zu dem Widder, der zwei Hörner hatte, den ich stehen sah vor dem Wasser, und er lief in seinem Zorn gewaltiglich auf ihn zu. [7] Und ich sah ihm zu, daß er hart an den Widder kam, und er ergrimmte über ihn, und stieß den Widder, und zerbrach ihm seine zwei Hörner. usw. usw."), eine Stelle, die traditionell auf Alexander gedeutet wurde (z. B. von Johannes Chrysostomos ${ }^{49}$ ). Diese schriftliche Weissagung aus dem Tempel des Apollon wird als $\beta \alpha \sigma \imath \lambda o \gamma \rho \alpha ́ \varphi \varphi v ~ b e z e i c h n e t$. Alexander zeigte sie den „Philosophen“, die sie ihm deuten sollten. Sie antworteten mit Dan. 8.20-22 (,[20] Der Widder mit den zweien Hörnern, den du gesehen hast, sind die Könige in Medien und Persien. [21] Der Ziegenbock aber ist der König in Griechenland.

47 Dazu gleich S. $168-170$.

48 Anonymi Byzantini Vita Alexandri regis Macedonum, ed. J. Trumpf. Stuttgart 1974,

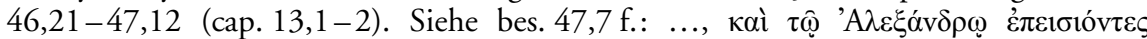

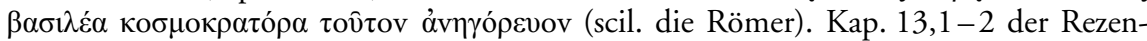
sion $\varepsilon$ ist sicher der Ausgangspunkt für die ausführlichere Geschichte von Alexanders Romaufenthalt in der mittelgriechischen Fassung des Alexanderromans.

49 Siehe die Belege bei H.J. Gleixner, Das Alexanderbild der Byzantiner. Inaug.-Diss. München 1961, $5 \mathrm{f}$. 
Das große Horn zwischen seinen Augen ist der erste König. [22] ..."). Alexander wird auf Grund dieser göttlichen Weissagung zum Kosmokrator erklärt. ${ }^{50}$

Es wird also völlig klar, daß es sich bei dem $\beta \alpha \sigma i \lambda o \gamma \rho \alpha ́$ ́ıv um Weissagungen des Propheten Daniel handelte, die sich auf auserwählte Herrscher, hier Alexander den Großen, beziehen. Zu bedenken ist weiterhin, daß mit der $\varepsilon$-Rezension aus dem 8. Jh. (?) eine massive Christianisierung Alexanders, seine Angleichung an den byzantinischen christlichen Kaiser, erfolgte. ${ }^{51}$

Verschiedene Rezensionen des byzantinischen Alexanderromans $(\gamma, \varepsilon, \lambda)$ wurden nach dem ausgehenden 7. Jh. bzw. im 8. oder 9. Jh. mit Stellen aus der Apokalypse des Pseudo-Methodios interpoliert (die „unreinen Völker“ Gog und Magog, Alexanders Bau der Mauer, die Gog und Magog von der Ökumene aussperren sollte), so daß sich hier ein weiterer - bisher nicht beachteter Zusammenhang zwischen der apokalyptischen Literatur und den mittel- und spätbyzantinischen Alexanderdichtungen ergibt. ${ }^{52}$

Die Interpretation des Begriffs $\beta \alpha \sigma i \lambda o \gamma \rho \alpha \varphi \varepsilon i ̂ o v$ macht es aber auch notwendig, die lateinische Literatur des 13. Jhs. zu berücksichtigen. Es ergibt sich hier die günstige Konstellation, daß die Klärung der eigentlichen Bedeutung eines byzantinischen terminus technicus durch einige wichtige Schriften des Westens, die u. a. eine große Rolle in der Forschung zum Stauferkaiser Friedrich II. spielen, wesentlich gefördert wird.

Namentlich sind die sog. Erythräische Sibylle ${ }^{53}$ mit ihrer so bedeutsamen und wirkmächtigen Sentenz zu Friedrich, vivit et non vivit, ${ }^{54}$ sowie die Chronik

50 Mitsakis, Der byzantinische Alexanderroman nach dem Codex Vindob. Theol. gr. 244 (wie Anm. 42), 52 f.; vgl. Gleixner, Das Alexanderbild (wie Anm. 49), 77; Lolos, Ps.Kallisthenes: Zwei mittelgriechische Prosa-Fassungen des Alexanderromans, I (wie Anm. 42), 44,3, p. 186-187, bietet die gleiche Geschichte.

51 Moennig, Rezension * (wie Anm. 42), 113-123 (mit der älteren Literatur).

52 Siehe Gleixner, Das Alexanderbild (wie Anm. 49), 56 f.; J. Trumpf, Alexander, die Bersiler und die Brüste des Nordens, BZ 64 (1971) 326-328; Moennig, Rezension *ל (wie Anm. 42), 112 ff.; Trumpf bei Merkelbach, Die Quellen des griechischen Alexanderromans (wie Anm. 42), 149, 204; G. Reinink, Die Entstehung der syrischen Alexanderlegende als politisch-religiöse Propagandaschrift für Herakleios' Kirchenpolitik, in: After Chalcedon. Studies in Theology and Church History, offered to Professor Albert van Roey for his Seventieth Birthday, ed. by C. Laga/J.A. Munitiz/L. van Rompay (OLA 18). Leuven 1985, 263-281; Ders., Alexandre et le dernier empereur du monde: les développements du concept de la royauté chrétienne dans les sources syriaques du septième siècle, in: Alexandre le Grand dans les littératures occidentales et procheorientales. Paris 1999, 149-159.

53 In der Überschrift taucht der Begriff Vasilographo auf - siehe dazu unten S. 175. Zur Erythräischen Sibylle (Sibilla Erithea) siehe I. Cervelli, Questioni sibilline, Studi storici 34 (1993) 895-1001, hier bes. 955 ff. (die ältere Bibliographie) und jetzt die umfassende Untersuchung von Chr. Jostmann, Sibilla Erithea Babilonica. Papsttum und Prophetie im 13. Jahrhundert (MGH-Schriften, 54). Hannover 2006, 228-233 und passim, der jetzt zu den folgenden Ausführungen zu vergleichen ist. 
des Salimbene de Adam ${ }^{55}$ zu nennen. Beide kennen und verwenden den Begriff

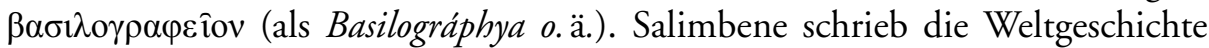
(chronica) des Sicard von Cremona $(\dagger 1215)$ aus. Vielleicht benutzte er zusätzlich zu Sicard aber auch noch eine „palästinensisch-byzantinische Geschichte“, wie Dove vermutete (für die Jahre 1186-1205). ${ }^{56}$ Bis zum Jahre 1212 ist sein Text im Wesentlichen der des Sicard. Dieser hatte selbst am 4. Kreuzzug teilgenommen, und man kann annehmen, daß er Gelegenheit hatte, direkt mit Byzantinern in Kontakt zu kommen. ${ }^{57}$ Seine Definition des Begriffs

54 Dem Zitat aus der Erythräischen Sibylle (die man nun, nach Jostmanns Arbeit, Sibilla Erithea nennen muß), mit dem Ernst Kantorowicz sein berühmtes Buch über Friedrich II. schloß (siehe E. Kantorowicz, Kaiser Friedrich der Zweite. Stuttgart ${ }^{3} 1992$, 632). Zur Bedeutung siehe H. Möhring, Der Weltkaiser der Endzeit. Entstehung, Wandel und Wirkung einer tausendjährigen Weissagung (Mittelalter-Forschungen, 3). Stuttgart 2000, 240 und jetzt besonders Jostmann, Sibilla Erithea (wie Anm. 53).

55 Salimbene de Adam, Cronica I, ed. G. Scalia (CCCM 125A). Turnhout 1998, p. 35 (cap. 33,34-34,4): Deinde Basilográphya, id est regalis scriptura cuisdam prophete Danielis Achivi, qui de imperatorum Constantinopolitanorum successionibus enigmata scripsit, producitur in medio. Ubi cum legeretur quod natio flava cesarie ventura esset urbis excidio urbemque gravi expugnatura prelio, tamen ad ultimum (quod in ipsos decidat!) peritura, hoc facto confissi Achivi repente irruunt in Latinos. Scalia a.a.O. p. 37 (c. 35,28-32): Adimpleta est itaque prophetia, quam mathematicus quidam predixit Achivus: (gaudete septem montes, sed non mille annos, Nondum enim a Constantino millesimus advenerat annus, quando Septemsolium, id est Constantinopolis, a summo gaudio tristicie ruit in yma. Vgl. zu dieser Stelle jetzt Jostmann, Sibilla (wie Anm. 53), $228 \mathrm{f}$. Zu gaudete septem montes, sed

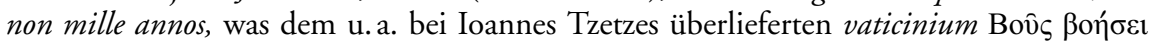

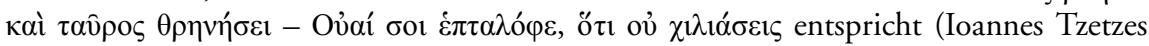
epistulae, rec. P.A.M. Leone. Leipzig 1972, 88,5 f. [Nr. 59 - dazu M. Grünbart, Prosopographische Beiträge zum Briefcorpus des Ioannes Tzetzes, JÖB 46 [1996] 175-226, hier 209]; ausführlich besprochen in Ioannis Tzetzae Historiae, rec. P.A.M. Leone. Neapel 1968, 369-371 [IX 608-678]); vgl. auch „Die letzte Vision Daniels“, in

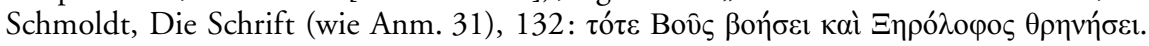
Siehe noch Pertusi, Fine di Bisanzio (wie Anm. 27), 122; W. Brandes, Konstantinopels Fall im Jahre 1204 und „apokalyptische“ Prophetien, in: Syriac Polemics. Studies in Honour of G.J. Reinink, ed. by W.J. van Bekkum/J.W. Drijvers/A.C. Klugkist (OLA 170). Leuven 2007, 239-259; Mango, ZRVI 6 (1960) 62. Zu Ioannes Tzetzes siehe C. Wendel, RE VII A 2 (1948) 1959-2011, bes. 1996. Zu Salimbene siehe W. Koller, LexMa VII (1995) 1302; Salimbeniana. Atti del Convegno per il VII Centenario di Fra Salimbene (Parma 1987/1989). Bologna 1991; O. Guyotjeannin, Salimbene de Adam: un chroniqueur franciscain. Turnhout 1995; grundlegend ist die Einleitung von Scalia a.a.O., VIIff.

56 A. Dove, Die Doppelchronik von Reggio und die Quellen Salimbenes. Leipzig 1873, 117; O. Holder-Egger, Über die verlorene größere Chronik Sicards von Cremona, NA 29 (1904) $177-245$.

57 Siehe zu ihm M.-A. Aris, LexMa VII (1995) 1833 (mit der wichtigsten Literatur). Da Sicards Chronik zu großen Teilen nur durch Salimbene überliefert ist, muß dieser zitiert werden, zumal Holder-Egger in seiner Edition des Chronik des Sicard (MGH SS 31. Hannover 1903, 22-183) die bei Salimbene erhaltenen Passagen des Sicard wegließ. 
entspricht der bisher aus griechischen Quellen gewonnenen Präzisierung im Sinne einer pseudepigraphischen Weissagung über das zukünftige Schicksal byzantinischer Kaiser, die dem alttestamentlichen Propheten Daniel zugeschrieben wurde: „Basilographia ist eine königliche Schrift (regalis scriptura) eines gewissen Propheten Daniel des Achäers, der über die Abfolge der Kaiser Konstantinopels ,Rätselhaftes' schrieb. ${ }^{\text {"58 }}$ Diese Notiz ist zum Jahr 1203, also in die unmittelbare Vorgeschichte der beiden Eroberungen (1203 und 1204) Konstantinopels durch die Kreuzfahrer, eingeordnet. Man beachte die Ver-

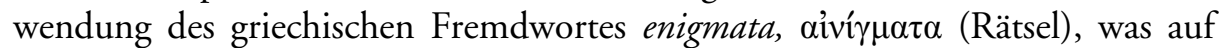
einen griechischen Ursprung der Kenntnisse Sicards bzw. Salimbenes deuten könnte und an den griechischen Titel der „Rätsel Leons des Weisen“ (Aïvv $\gamma \mu \alpha$

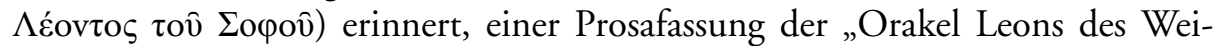
sen“, die man, worauf schon hingewiesen wurde, ${ }^{59}$ auch als basileiographeion bezeichnete. $^{60}$

Agostino Pertusi machte vor einigen Jahren auf eine bisher noch ungedruckte Chronik eines Venezianers namens Marco aufmerksam, die - nach eigener Angabe - im Jahr 1292 niedergeschrieben wurde. ${ }^{61}$ Unmittelbar nach-

Zum Text des Sicard, den Salimbene überliefert, siehe immer noch Dove, Die Doppelchronik von Reggio und die Quellen Salimbenes (wie Anm. 56), 109-143; vgl. jetzt Scalia, Salimbene de Adam (wie Anm. 55), XII-XXXI, wo die umfangreiche Literatur ausgewertet wird.

58 Text in Anm. 55.

59 Siehe oben S. 163.

60 Vgl. auch J. Vereeken/L. Hadermann-Misguich, Les oracles de Léon le Sage illustrés par Georges Klontzas (Oriens Graecolatinus, 7). Venise 2000, 23 f.; The Oracles of the Most Wise Emperor Leo and The Tale of the True Emperor (Amstelodamensis Graecus VI E 8). Text, translation and introduction, ed. by W.G. Brokkaar et al. Amsterdam 2002, 25; grundlegend bleibt C. Mango, The Legend of Leo the Wise, ZRVI 6 (1960) 59-93 (auch in Ders., Byzantium and Its Image. History and Culture of the Byzantine Empire and its Heritage. London 1984, Nr. XVI), hier $71 \mathrm{f}$.

61 A. Pertusi, Le profezie sulla presa di Constantinopoli (1204) nel cronista veneziano Marco (c. 1292) e le loro fonti bizantine (Pseudo-Costatino Magno, Pseudo-Daniele, Pseudo-Leone il Saggio), Studi Veneziani n.s. 3 (1979) 13-46, hier 15 mit Anm. 5 (auch in: Ders., Saggi Veneto-Bisantini [Civiltà Veneziani. Studi 37]. Firenze 1990, 315-48) bzw. Ders., Fine di Bisanzio (wie Anm. 27), 68 mit Anm. 198; insbes. ist auf A. Carile, La cronachistica Veneziana (secoli XIII-XVI) di fronte alla spartizione della Romania nel 1204 (Civiltà Veneziana Studi, 25). Firenze 1969, 77 ff., 90, 178 f., zu verweisen. Siehe aber schon G. Waitz, Reise nach Italien im Frühjahr 1876, NA 2 (1877) 325-381, hier 350 ff. zur Hs.; und jetzt Jostmann, Sibilla (wie Anm. 53), 230 f. Die Hs. (Ven. marc. It. 124 [n. 6802]) selbst stammt aus dem Jahr 1503 und wurde aus einer Vorlage des Jahres 1430 kopiert. Der Archetyp stammt aus dem ausgehenden 13. Jh. (nach 1292). Marco selbst nennt im Vorwort den März 1292 als Datum seiner Niederschrift, doch dürfte diese Kompilation in den folgenden Jahren entstanden sein. Schon H. Simonsfeld, Venetianische Studien I. Das Chronicon Altinate. München 1878, $55 \mathrm{f}$. sah in ihm einen von Endzeitängsten geplagten Franziskanermönch (freundlicher Hinweis von Johannes Fried). 
dem er den Text des berühmten Vertrags zwischen Enrico Dandalo, dem Venezianischen Dogen, der für die bekannte „Ablenkung“ des 4. Kreuzzugs verantwortlich war, ${ }^{62}$ und den anderen Anführern des Kreuzzugs aus dem Jahr $1204,{ }^{63}$ in dem die byzantinische Beute aufgeteilt wurde, darbot, bietet Marco drei Übersetzungen aus dem Griechischen, die im Kontext der hier untersuchten Problematik von großem Interesse sind. „Es beginnt die Prophetie über Konstantinopel, gefunden in einem Basiligrapheion" (Incipit prophecia de Constantinopolim inventa in quodam Paragrapho [leg. Vasilographo]). ${ }^{64}$

Pertusi ermittelte die griechischen Vorlagen und edierte sie z.T. neu. Es handelt sich bei dem ersten Text, „Erzählung über Konstantinopel, gegründet vom großen Konstantin" (Narracio de Constantinopolim, quando condita est a Magno Constantino), um die lateinische Übersetzung eines bekannten griechischen Textes, der „Weissagung des zu den Heiligen zählenden Konstantin des Großen über den Untergang der großen Stadt (scil. Konstantinopel)" (Прó $\rho-$

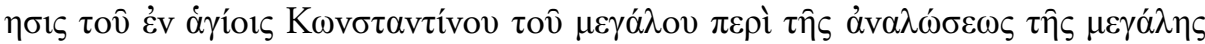
$\tau \hat{\omega} \mathrm{v} \pi \hat{\lambda} \lambda \varepsilon \omega \mathrm{v}) .{ }^{65}$ Dieser kurze Text (ca. 2 Druckseiten) ist eine apokalyptische Geschichte der Stadt Konstantinopel und damit eine des Byzantinischen Reiches, denn Hauptstadt und Reich waren identisch. Fiel die Stadt, mußte auch das Reich vergehen. Daß hier Konstantin der Große in der Rolle der sonst üblichen Propheten oder Kirchenväter erscheint, die als Autoren dieser pseudepigraphischen Apokalypsen auftauchen, ist nicht verwunderlich. Es gibt aus der byzantinischen Spätzeit mehrere Weissagungen, was natürlich Untergangsweissagungen bedeutet, die angeblich von Konstantin dem Großen herrühren. Der Text des Marco beweist, daß diese mit Konstantin dem Großen in Verbindung stehenden Weissagungen aus der Zeit um 1453 bereits im 13. Jh. existierten. ${ }^{66}$

62 Siehe zu ihm Th.F. Madden, Enrico Dandolo and the Rise of Venice. Baltimore 2003.

63 G.L.F. Tafel/G.M. Thomas, Urkunden zur älteren Handels- und Staatsgeschichte der Republik Venedig (Fontes rerum Austriacarum, Abt. 2, Diplomataria et acta, 12), I. Wien 1856, 444-452; A. Carile, Partitio terrarum imperii Romanie, Studi Veneziani 7 (1965) 125-305; vgl. M. Angold, The Fourth Crusade. Event and Context. Harlow 2003, 99 f.; D.E. Queller/Th.F. Madden, The Fourth Crusade. The Conquest of Constantinople. Philadelphia ${ }^{2} 1997,175 \mathrm{f}$.

64 Die drei Texte finden sich ff. 78r-79v. Die Konjektur Pertusis (paragrapho zu vasilographo, besser wäre: vasilographio) ist sehr berechtigt. Schon die Tatsache, daß in den folgenden Texten (1. 63 und 68) an prominenter Stelle nochmals vasilographio auftaucht, spricht dafür. Siehe auch Jostmann, Sibilla (wie Anm. 53), $232 \mathrm{f}$.

65 Pertusi, Studi Veneziani n.s. 3 (1979) 22-23; Ders., Fine di Bisanzio (wie Anm. 27), 54-56; vgl. schon Istrin, Otkrovenie (wie Anm. 31), 6.

66 Gennadii Scholarii expositio litterarum quae in sepulcro Constantini Magni inscriptae erant (nach der Ausgabe von A. Banduri), in: PG 160, 768-773; vgl. J. Bick, Die kryptographische subscriptio im Cod. Vind. phil. Gr. 231, WSt 36 (1914) 332-337, hier 333; Pertusi, Studi Veneziana n.s. 3 (1979) 36 mit Anm. 36. Siehe W. Brandes, Der Fall Konstantinopels 1453 als apokalyptisches Ereignis, in: Geschehenes und Ge- 
Die griechische Vorlage des Venezianers Marco hatte offensichtlich eine andere Überschrift, was in keiner Weise Anstoß erregen kann, denn nichts ist in der handschriftlichen Überlieferung griechischer apokalyptischer Texte instabiler als die Titel derartiger Texte, ${ }^{67}$ die auch selbst fortwährenden Veränderungen unterworfen waren (quot manuscripti tot recensiones). Entsprechend sollte man gewisse Differenzen zwischen dem bekannten griechischen Text (dessen Handschriften aus dem 15./16. Jh. stammen) und der Übersetzung des Marco nicht überbewerten. Der Text selbst versammelt eine ganze Anzahl der stereotypen Untergangsweissagungen, wie sie aus den verschieden Daniel-Apokalypsen, der Apokalypse des Pseudo-Methodios, der Bibel usw. bekannt sind. Es ist mit einigem Recht vermutet worden, daß er als unmittelbare Reaktion auf die Eroberung Konstantinopels durch die Teilnehmer des 4. Kreuzzuges im Jahre 1204 entstand. ${ }^{68}$ Dafür spricht z. B. auch, daß die Großfeuer, die 1203/1204 in Folge der Angriffe ausbrachen und große Teile der Stadt zerstörten, eigens thematisiert werden. Dies durchbricht das sonst übliche Schema der apokalyptischen Schilderungen des Untergangs Konstantinopels. An sich ging man in der Regel davon aus, daß am Ende der Zeiten die byzantinische Hauptstadt im Meer versinken werde. ${ }^{69}$ Es gibt weitere Hinweise im Text, die sich auf die Ereignisse von 1204 beziehen lassen. ${ }^{70}$

Der zweite lateinische Text, „Über das Basilographeion über die Stadt, auf welche Weise sie in Brand geriet und den Lateinern übergeben wurde" (De Vasilographio de Urbe, quomodo incendenda erat et tradenda Latinis [sic!]), basiert

schriebenes. Beiträge zu Ehren von G.St. Henrich und K.-P. Matschke, hg. von S. Kolditz /R.C. Müller. Leipzig 2005, 453-470. Siehe aber schon oben Anm. 36 zu den Parastaseis syntomoi chronikai.

67 Die - neben der Apokalypse des Pseudo-Methodios - am häufigsten überlieferte byzantinische Apokalypse, die „Letzte Vision des Propheten Daniel“ (siehe schon oben Anm. 31), findet sich (u.a.) mit folgenden Überschriften in verschiedenen Hand-

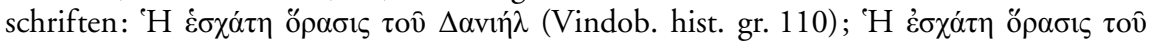

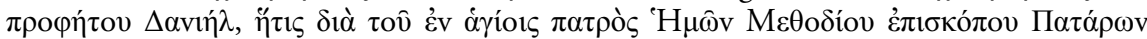

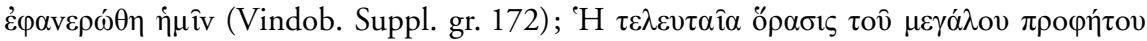
$\Delta \alpha v i \eta ́ \lambda$ (Vindob. jur. gr. 6) usw. Weitere Varianten bei Schmoldt, Die Schrift (wie Anm. 31), 122 im app. crit. verzeichnet.

68 Pertusi, Fine di Bisanzio (wie Anm. 27), 52; Vereeken/Hadermann-Misguich, Les oracles de Léon le Sage (wie Anm. 60), 119 f.

69 Vgl. W. Brandes, Das „Meer“ als Motiv in der byzantinischen apokalyptischen Literatur, in: Griechenland und das Meer. Beiträge eines Symposions in Frankfurt im Dezember 1996, hg. von E. Chrysos/D. Letsios/H.A. Richter/R. Stupperich (Peleus. Studien zur Archäologie und Geschichte Griechenlands und Zyperns, 4). Mannheim/Möhnesee 1999, 119-131.

70 So z. B. die Erwähnung eines „Jünglings“, was wohl auf Alexios IV. zu beziehen ist, der eine so unglückliche Rolle bei der Ablenkung des 4. Kreuzzugs spielte. Vgl. zuletzt zu ihm Angold, The Fourth Crusade (wie Anm. 63), passim. Zum apokalyptischen meirakion siehe unten bei Anm. 145 . 
auf einer bekannten griechischen Daniel-Apokalypse. ${ }^{71}$ Auch er bezieht sich zweifellos auf die Ereignisse von 1204, u. a. taucht mehrfach die flava gens auf, die $\xi \alpha v \theta \dot{\alpha}$ č $\theta v \eta$ der griechischen Überlieferung, die „blonden Völker“ bzw. das „blonde Volk“, wie die europäischen Kreuzfahrer in dieser Zeit von den Byzantinern genannt wurden. ${ }^{72}$

Der dritte lateinische Text (ohne Titel) ist die Übersetzung eines byzantinischen Orakeltextes - oft Kaiser Leon dem Weisen zugeschrieben -, der ebenfalls die Eroberung der Stadt durch die Teilnehmer des 4. Kreuzzugs (1204)

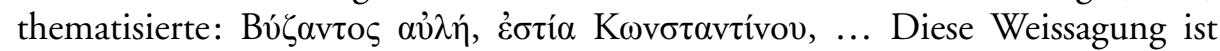
erstaunlich umfangreich überliefert. ${ }^{73}$ Ich zitiere die deutsche Übersetzung von Ellissen aus dem Jahre 1857 (mit einigen Korrekturen): „Hofstatt des Byzas, Konstantinos' heiliger Herd, - Du neue Roma, Babel und Jerusalem, - noch dreimal drei Jahrhunderte der Herrschaft sind - Dir zuerkannt, nur zwei Jahrzehnte fehlen daran. - So lange sammelst du der Völker Gold, wie Staub, Oberherrschend deine Nachbarn ringsum allzumal. - Dann aber legt ein fremdes blondes Volk - In Asche dich und löst die Fugen deiner Macht. ..."74 Die genannten Zahlenangaben führen auf das Jahr 1204, 324 als Gründungsdatum Konstantinopels vorausgesetzt. Im Codex Parisinus graecus 426 wurde dieser Text, wie schon gesagt, als $\beta \alpha \sigma \imath \lambda o \gamma \rho \alpha \varphi \varepsilon$ îov bezeichnet. ${ }^{75}$ Dieses Orakel endet jedoch, anders als die beiden anderen Texte, optimistisch. Er bezieht sich vermutlich auf die Rückgewinnung Konstantinopels durch den byzantinischen

71 Pertusi, Studi Veneziani n.s. 3 (1979); Ders., Fine di Bisanzio (wie Anm. 27), 72 -73 (lateinischer Text); schlechtere Ausgabe bei Istrin, Otkrovenie (wie Anm. 31), $318 \mathrm{f}$, dessen Text allerdings länger ist ( $\$ \$ 2-5$ nur bei Istrin).

72 Siehe Pertusi, Fine di Bisanzio (wie Anm. 27), 62-109. In früheren Jahrhunderten bezeichnete der Begriff die Russen, d.h. die Waräger, und noch früher (in der Spätantike) germanische und slawische Völkerschaften. Vgl. H. Wolfram, Byzanz und die Xantha Ethne (400-600), in: Das Reich und die Barbaren, hg. von E.K. Chrysos/A. Schwarcz (Veröffentlichungen des Instituts für Österreichische Geschichtsforschung, 29). Wien/ Köln 1989, 237-246.

73 PG 107, 1149A/B (Lambeck nach Löwenklau) - Fortsetzung in PG 135, 319-322 in not. 35; N. Bees, BNJ 13 (1936/1937) 244ß'; Pertusi, Studi Veneziani n.s. 3 (1979) 24 f.; Ders., Fine di Bisanzio (wie Anm. 27), 74 (in app.); E. Mioni, Gli oracoli dello Pseudo-Leone (tre carmi dell'età dei Paleologi), in: Lirica Greca da Archiloco a Elitis. Studi in onore di Filippo Maria Pontani (Università di Padova, Studi bizantini e neogreci, 14). Padova 1984, 291-308, hier 302, vgl. auch 298 ff. zu den Hss. und den früheren Drucken (dazu auch Mango, ZRVI 6 [1960], 79 f., 82-84); Vereeken/Hadermann-Misguich, Les oracles de Léon le Sage (wie Anm. 60), 124. Es gibt sogar verschiedene Übersetzungen: eine deutsche von A. Ellissen, Analekten der mittel- und neugriechischen Literatur III. Leipzig 1857, 96; eine französische Übersetzung bei Vereecken/Hadermann-Misguich a.a.O. 125 sowie eine italienische bei Pertusi, Fine di Bisanzio, 52.

74 Ellissen, Analekten (wie Anm. 73) III, 96.

75 Siehe schon oben S. 163 mit Anm. 33 und 34. 
Kaiser Michael VIII. im Jahre $1261 .{ }^{76}$ „Erneuert stehst Du da auf's neu, beherrschest die Nationen weiser, als vordem. Das Haus der Herrlichkeit des Höchsten wirst alsdann Du heißen und die Nachbarn Dir zu Füßen sehn."

Es ist hier nicht der Ort, um näher auf inhaltliche Fragen einzugehen. Festzuhalten ist, daß es sich bei den Übersetzungen des Venezianers Marco im Jahre 1292 um typische byzantinische prophetisch-apokalyptische Texte handelt, die den Fall Konstantinopels voraussagten, ein Hauptthema der byzantinischen Apokalyptik (neben dem Endzeitkaiser, dem Antichrist, dem Jüngsten Gericht usw.).

Offenbar nutzte man diese Texte in Venedig, um die Ereignisse des Jahres $1204 \mathrm{zu}$ rechtfertigen, ${ }^{78}$ die angesichts der allgemein geäußerten Kritik in ganz Europa inzwischen als „peinlich“ empfunden wurden. ${ }^{79}$ Die Eroberung Konstantinopels durch „blonde Völker“ wurde ja in verschiedenen Weissagungen der byzantinischen Hauptstadt angedroht. Der Fall der Stadt eben durch „blonde Völker“ im Jahre 1204 bewies dann letztlich nur, daß diese Texte richtig die Zukunft beschrieben hatten. Die Venezianer und ihre Machinationen, die zur Katastrophe von 1204 führten, hatten also nichts anderes getan, als Gottes Willen zu erfüllen. Die Plünderung und Schändung der größten Stadt der damaligen Christenheit war also eigentlich ein Werk, das allein der Verwirklichung der Pläne Gottes diente, die von demselben Gott mit Sicht auf die Zukunft ausgestattete Propheten der Byzantiner selbst vorausgesagt hatten. Auf der anderen Seite, dies sei ergänzend erwähnt, vermied man über einen langen Zeitraum hinweg im historischen Gedächtnis der Serenissima selbst eine Erinnerung an die Ereignisse von 1204 und die erfolgreich realisierten Pläne des Dogen Enrico Dandolo. Selbst die zahllosen „Beutestücke“ (man denke nur an die zahllosen Reliquien, die Tetrarchenstatue oder die bekannte Quadriga, an deren Herkunft aus Konstantinopel man sich erst im 15. Jh. wieder erinnerte), denen man allenthalben in Venedig begegnen konnte, wurden ihres historischen

76 Siehe zuletzt Vereecken/Hadermann-Misguich, Les oracles de Léon le Sage (wie Anm. 60), $191 \mathrm{f}$.

77 Ellissen, Analekten a.a.O.

78 Vgl. J. Fried, Schuld und Mythos. Die Eroberung Konstantinopels im kulturellen Gedächtnis. Ich danke Herrn Fried an dieser Stelle für seine Freundlichkeit, mir sein ungedrucktes Vortragsmanuskript zur Verfügung zu stellen. Siehe schon die kurzen Bemerkungen von J. Fried, Der Schleier der Erinnerung. Grundzüge einer historischen Memorik. München 2004, 162 f.; vgl. auch E. Siberry, Criticism of Crusading, 10951274. Oxford 1985, bes. 173 f.; Angold, The Fourth Crusade (wie Anm. 63), $111 \mathrm{ff}$.

79 Natürlich ist diese Darstellung stark verkürzt. Daß die Art und Weise, wie Venedig an der „Ablenkung“ des vierten Kreuzzuges beteiligt war, durch eine komplizierte und mehrschichtige Motivlage gekennzeichnet war, haben D.E. Queller/G.W. Day, Some Arguments in Defense of the Venetians on the Fourth Crusade, AHR 81 (1976) 717 737, gezeigt. 
Ursprungs entkleidet. ${ }^{80}$ Man registrierte die Eroberung Konstantinopels zwar in der historischen Erinnerung der Stadt, aber wenn man sich, um nur ein Beispiel zu nennen, den Bericht des 1354 gestorbenen Dogen und Chronisten Andrea Dandolo $^{81}$ über die Vorgänge von 1204 anschaut, so fällt die nüchterne und aufs Wesentliche reduzierte Darstellung auf; ein Triumphgefühl läßt sich nicht entdecken. Die allenthalben geäußerte Kritik, etwa des Papstes Innozenz III., wird ignoriert. Diese Nüchternheit wird nur kurz durch ein längeres Zitat aus der Sibilla Erithea Babylonica durchbrochen. ${ }^{82}$ Es sollte beweisen, daß die Er-

80 Fried, Schuld und Mythos (wie Anm. 78).

81 Andreae Danduli ducis Venetiarum Chronica per extensum descripta aa. 46-1280 d. C. , a cura die E. Pastorello (RIS 12/1). Bologna 1937, 279. Zur Person siehe A. Menniti Ippolito, LexMa III (1986) $490 \mathrm{f}$.

82 A.a.O. 279,20-23. Es folgt die wahrscheinlich unrichtige Behauptung, Enrico Dandolo sei als venezianischer Gesandter am Hofe Manuels I. geblendet worden. Auch dies ist ein Versuch, vom Unrecht der venezianischen Aktion des Jahres 1204 abzulenken. Vgl. Angold, The Fourth Crusade (wie Anm. 63), 55 mit Verweis auf die Historia ducum Veneticorum, ed. H. Simonsfeld. MGH SS XIV. Hannover 1883, 81,11, die von der unversehrten Rückkehr der fraglichen Gesandtschaft des Jahres 1171 berichtet. Auch Fried, Schuld und Mythos (wie Anm. 78) bezweifelt die Geschichte und sieht hier „Legitimitätsnachweis und Rache ... statt Lobpreis und Mehrung. Nüchterne Aufzählung statt eines Triumphgesangs“. Für die Blindheit (jedoch nicht für eine Blendung auf Befehl Manuels I.!) sprechen mehrere Quellen: u.a. Geoffroy de Villardouin, der mitteilte, daß Dandolo ein alter Mann war und „überhaupt nichts sah“ (..., qui vialx hom ere et gote ne veoit, ...; E. Faral, Villehardouin - La conquête de Constantinople, I. Paris ${ }^{5}$ 1973, 174 [cap. 173]; Chroniken des Vierten Kreuzzugs. Die Augenzeugenberichte von Geoffroy de Villardouin und Robert de Clari. Ins Neuhochdeutsche übersetzt, eingeleitet und erläutert von G.E. Sollbach [Bibliothek der historischen Forschung, 9]. Pfaffenweiler 1998, 58); Gunther von Pairis, Hystoria Constantinopolitana. Untersuchungen und kritische Ausgabe von P. Orth (Spolia Berolinensia, 5). Hildesheim/Zürich 1994, 14,12 f.: Erat autem ibi vir quidam prudentissimus, dux videlicet Venetorum, cecus quidem in facie, ...; vgl. The Capture of Constantinople. The Hystoria Constantinopolitana of Gunther of Pairis, ed. and transl. by A.J. Andrea. Philadelphia 1997, 97; die „erste Nowgoroder Chronik“" (A.N. Nasonov, Novgorodskaja pervaja letopis’ staršego i mladšego izvodov. Moskva/Leningrad 1950, 49; vgl. G. Podskalsky, Christentum und theologische Literatur in der Kiever Rus' [988-1237]. München 1982, 229-231) erwähnt dies: „... der blinde Duž von der Markusinsel Venedik. Diesen Duž hatte Kaiser Manuel blenden lassen; ..." (Übersetzung nach D. Freydank, Die altrussische Erzählung über die Eroberung Konstantinopels 1204 [Chronista Novgorodensis], BSl 29 [1968] 334-359, hier 343). Zum Problem grundlegend Th.F. Madden, Venice and Constantinople in 1171 and 1172: Enrico Dandolo's Attitudes Towards Byzantium, Mediterranean Historical Review 8 (1993) 166-185; Ders., Enrico Dandolo (wie Anm. 62), 63-68. Zur zeitgenössischen Kritik an der Rolle Venedigs beim 4. Kreuzzug siehe H. Roscher, Papst Innozenz III. und die Kreuzzüge (Forschungen zur Kirchen- und Dogmengeschichte, 21). Göttingen 1969, 113-131; A.J. Andrea, The Historia Constantinopolitana: An Early Thirteenth-Century Cistercian Looks at Byzantium, Analecta Cisterciensia 36 (1980) 290-302, bes. 274-276; Belege und weitere Literatur bei Fried, Schuld und Mythos. 
oberung und Schändung einer christlichen Stadt durch die Teilnehmer an einem ursprünglich gegen die antichristlichen Muslime gerichteten Kreuzzuges nur die Erfüllung eines längst festgelegten Schicksals war. Stattdessen erfand und feierte man in Venedig jahrhundertelang einen angeblichen großartigen Sieg über Friedrich Barbarossa im Jahre 1177, der gleichsam den „Ersatztriumph“ für 1204 darstellte, wie Johannes Fried gezeigt hat. ${ }^{83}$

Die Übersetzung von Texten der griechischen Orakelliteratur im 13. Jh. war nicht auf den erwähnte Marco und sein umfangreiches Geschichtswerk beschränkt. An der Kurie in Rom entstanden um 1300 die bekannten und oft behandelten Papstvaticinien (vaticinia pontificum) mit ihren eindrucksvollen Illustrationen. Ihre Grundlage waren die „Orakel Leons des Weisen“, wie man seit geraumer Zeit weiß. Bemerkenswert aus der Sicht der Byzantinistik ist die souveräne Adaption östlicher Kaiserorakel und ihre Projektion auf das Papsttum. $^{84}$

Die bereits mehrfach erwähnte Sibilla Erithea weist eine Besonderheit auf, die sie auch im hier untersuchten Zusammenhang interessant macht. ${ }^{85}$ Ihre Überschrift besagt: „Diese Schrift stammt aus einem Buch, das vasilographo genannt wird, d.h. kaiserliche Schrift (imperialis scriptura), welche die Sibylla Erithea Babylonica zusammenstellte auf Bitten der Griechen bezüglich Priamos', des Königs Trojas, welche der höchst gelehrte Vater Vedoxa aus dem Chaldäischen ins Griechische übersetzte, die dann aus der Schatzkammer Manuels, des Kaisers der Griechen, der Admiral des Königreichs Sizilien, Eugenius, aus dem Griechischen ins Lateinische übersetzte. ${ }^{\text {"86 }}$ Es kann an dieser Stelle nicht meine

83 Fried, Schleier der Erinnerung (wie Anm. 78), 157-166.

84 H. Grundmann, Die Papstprophetien des Mittelalters, in: Ders., Ausgewählte Aufsätze, II: Joachim von Fiore (Schriften der MGH, 25/2). Stuttgart 1977, 1-57; siehe zuletzt The Late Medieval Pope Prophecies. The Genus nequam Group, ed. by M.H. Fleming (Medieval and Renaissance Texts and Studies, 204). Tempe/Arizona 1999; H. Millet, „Il libro delle immagini dei papi“. Storia di un testo profetico medievale (La corte dei papi, 9). Roma 2002; Dies., Les successeurs du pape aux ours. Histoire d'un livre prophetique médiéval illustré. Turnhout 2004, jeweils mit der älteren Literatur. Zu den Entstehungsumständen siehe bes. G.L Potestà, Dante profeta e i vaticini papali, Rivista di storia del cristianesimo 1 (2004) 67-88; S. Kelly, The „Visio Fratris Johannis“: Prophecy and Politics in Late-Thirteenth Century Italy, Florensia 8/9 (1994/1995) 7-42.

85 O. Holder-Egger, Italienische Prophetien des 13. Jahrhunderts, NA 15 (1890) 143-178 (Text: 155-173); siehe jetzt die neue Edition von Jostmann, Sibilla (wie Anm. 53), $498-527$.

86 Hic liber est extractus de libro qui dicitur Vasilographo, id est imperialis scriptura, quam Sibilla Erithea Babylonica condidit ad petitionem Grecorum empore Priami regis Troie; quem Vedoxa peritissimus pater in Grecum transtulit de Chaldeo [sermone], tandem de erario Emanuelis imperatoris Grecorum eductum Eugenius regni Sicilie admiratus de Greco transtulit in Latinum; ed. Holder-Egger (wie Anm. 85), 155. Siehe jetzt die neue Edition von Jostmann, Sibilla (wie Anm. 53), 498, mit partiell abweichendem Text (was aber für die hier traktierte Problematik nicht wichtig ist). 
Aufgabe sein, diese verwickelten Angaben im einzelnen zu verifizieren und zu deuten. ${ }^{87}$ Anmerken möchte ich lediglich, daß man den Hinweis auf eine Übersetzung aus dem „Chaldäischen“, womit m. E. ein syrischsprachiger Text (oder ein Text in einer anderen orientalischen Sprache) gemeint sein könnte, ${ }^{88}$ nicht ignorieren sollte, wie dies die bisherige Forschung tat.

87 Siehe u.a. P.J. Alexander, The Diffusion of Byzantine Apocalypses in the Medieval West and the Beginnings of Joachimism, in: Prophecy and Millenarianism. Essays in Honour of Marjorie Reeves, ed. by Ann Williams. Harlow 1980, 53-106 und insbesondere jetzt Jostmann, Sibilla (wie Anm. 53), passim; M. Reeves, The Influence of Prophecy in the Later Middle Ages. Oxford 1969. 56 f. und passim; H. Möhring, Der Weltkaiser der Endzeit (wie Anm. 54), bes. 240. Zu Eugenios von Palermo siehe A.Kazhdan, ODB 743; E. Jamison, Admiral Eugenius of Sicily. His life and Work. London 1957. Hinter Vedoxa verbirgt sich vermutlich Neilos Doxopatres. Zu ihm siehe A. Kazhdan, ODB 660 (leider hat Kazhdan in beiden Artikeln den Bezug zur Sibilla Erithea vergessen); H.G. Beck, Kirche und theologische Literatur im Byzantinischen Reich. München 1959, 619-621; V. Laurent, L'oeuvre géographique du moine sicilien Nil Doxopatri, EO 36 (1937) 5-30 (allerdings war er vermutlich nicht sizilianischer Herkunft). Daß Neilos Doxopatres aus dem „Chaldäischen“ übersetzt habe, erscheint eher unwahrscheinlich. Jedenfalls lassen die unter seinem Namen erhaltenen Schriften keine Kenntnis orientalischer Sprachen erkennen (siehe Hieroclis Synecdemus et Notitiae Graecae episcopatuum accedunt Nili Doxopatrii notitia patriarchatuum ..., ex rec. G. Parthey. Berlin

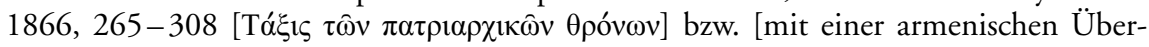

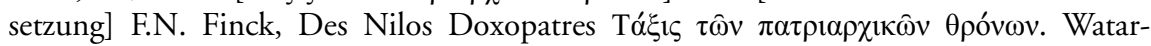
schapat 1902 [non vidi]; allerdings ist sein außerordentlich umfangreiches dogmatisches Werk [vgl. Beck a.a.O.] nur in wenigen Auszügen gedruckt: PG 120, 1292-1296; einige Athanasiosscholien in PG 25, 119, 433; PG 26, 116, 547, 555). Sein Aufenthalt $1142 / 1143$ am Hofe König Rogers II. in Palermo mag ihn in Italien bekannt gemacht haben.

88 Ein ausführlicher Textvergleich ist hier zwar nicht anzustellen, doch möchte ich auf einige orientalische Apokalypsen verweisen, die, wie die Sibilla Erithea, in Tiersymboliken schwelgen und die, auch wenn man sie kaum als direkte Vorlagen der lateinischen Sibilla Erithea bezeichnen kann, darauf verweisen, daß es in diversen orientalischen Sprachen apokalyptische Schriften gab, die mit der Sibilla Erithea verglichen werden sollten. Siehe - pars pro toto - die von F. Baethgen (Beschreibung der syrischen Handschrift „Sachau 131" auf der Königlichen Bibliothek zu Berlin, Zeitschrift für die alttestamentliche Wissenschaft 6 [1886] 193-211; vgl. auch J.-B. Chabot, L'apocalypse d'Esdras, Revue Sémitique 2 [1894] 242-250, 333-346; R. Gottheil, An Arabic Version of the Relevation of Ezra, Hebraica 4 [1887/1888] 14-17) edierte und übersetzte syrische Esra-Apokalypse (zu dieser vgl. auch A. Baumstark, Geschichte der syrischen Literatur. Bonn 1925, 71; CAVT 262; G. Reinink, Pseudo-Ephraems „Rede über das Ende " und die syrische eschatologische Literatur des siebenten Jahrhunderts, Aram 5 [1993] 437-463, hier 438; S. Brock, Syriac Sources for Seventh-Century History, BMGS 2 [1976] 17-36, hier 35). Auch die armenische Daniel-Apokalypse bietet interessantes Vergleichsmaterial (siehe P.Gr. Kalemkiar, Die siebente Vision Daniels, WZKM 6 [1892] 227-240; vgl. noch F. Macler, Les apocalypses apocryphes de Daniel, RHR 33 [1896]288-309; J. Issaverdens, The Uncanonical Writings of the Old Testament. Venedig 1934, 219-234; P.J. Alexander, The Oracle of Baalbek. The Tiburtine Sibyll in Greek Dress [DOS 10]. Washington D.C. 1967, 118 f.; Ders., Medieval 
Die vielfältigen Nachrichten der westlichen Kreuzzugshistoriker Geoffroy de Villehardoin, Gunther von Pairis, Robert de Clari oder auch des schon erwähnten Salimbene über Orakel in Konstantinopel, Abbildungen auf Säulen und geheimnisvolle Inschriften, die von den Byzantinern als Vaticinien gedeutet wurden, sind bekannt und brauchen hier nicht eigens vorgestellt zu werden. ${ }^{89}$ Es gibt sie seit dem ausgehenden 12. Jh., insbesondere in englischen Quellen (John of Salisbury, Roger of Howden, Radulf von Diceto), was nicht überrascht, denn schon Kaiser Alexios I. Komnenos $(1081-1118)$ rekrutierte mit Vorliebe Engländer (besonders Angelsachsen, die nach der normannischen Eroberung der Insel ihr Heil im fernen Byzanz suchten, wo sie auch gegen die verhaßten Normannen kämpfen konnten) für seine „Varägergarde“.90

Dieser Ausflug in die lateinische Literatur des 13. Jhs. hat gezeigt, daß in diesem Jahrhundert, als die Kontakte zwischen griechischem Osten und lateinischem Westen intensiver waren als lange Zeit zuvor (auch wenn die Ursachen dafür den Byzantinern mehr als schmerzhaft erschienen) eine Anzahl byzantinischer Orakel oder, wie man sie auch bezeichnen könnte: Kurzapokalypsen, ins Lateinische übersetzt wurden und daß angesichts der in der Regel ja wesentlich

Apocalypses as Historical Sources, AHR 73 [1968] 997-1018, hier 1002; A.-M. Denis, Introduction aux pseudépigraphes grecs d'Ancien Testament [Studia in Veteris Testamenti Pseudepigrapha, 1]. Leiden 1970, 312; Schmoldt, Die Schrift [wie Anm. 31], 264 ff.; Pertusi, Fine di Bisanzio [wie Anm. 27], 22 f.; Brandes, Apokalyptische Literatur [wie Anm. 27], 310; CAVT 264; Istrin, Otkrovenije [wie Anm. 31], 213). Es sei noch auf die sog. Bahīrā-Legende verwiesen, die direkt aus dem Syrischen ins Lateinische übersetzt wurde (siehe J. Bignami-Odier/G. Levi della Vida, Une version latine de l'apocalypse syro-arabe de Serge-Bahira, Mélanges d'archéologie et d'histoire 62 (1950) 125-148; B. Carra de Vaux, La légende de Bahira, ROC 2 (1897) 439-454; St. Gero, The Legend of the Monk Bahīrā, the Cult of the Cross and Iconoclasm, in: La Syrie de Byzance à l'Islam (VII - VIII ${ }^{\mathrm{e}}$ siècles), publ. par P. Canivet/J.-P. Rey-Coquais. Damas 1992, 47-57; Möhring, Der Weltkaiser der Endzeit (wie Anm. 54), 128-135; B. Roggema, The Legend of Sergius Bahîrâ: Some Remarks on its Origin in the East and its Traces in the West, in: East and West in the Crusader States. Context, Contacts, Confrontations, ed. by K. Ciggaar/H. Teule (OLA 92). Leuven 1999, 107-124 (mit der relevanten Literatur). Jostmann, Sibilla (wie Anm. 53), 314 und passim sieht mit Recht aber keine (bekannte) orientalische Vorlage.

89 Siehe zuletzt Jostmann, Sibilla Erithea (wie Anm. 53); Pertusi, Fine di Bisanzio (wie Anm. 27), 62 ff.; A.J. Andrea, Contemporary Sources for the Fourth Crusade (The Medieval Mediterranean, 29). Leiden/Boston/Köln 2000, 265 ff.; Mango, ZRVI 6 (1960) 72 f.; und jetzt Brandes, Die Eroberung Konstantinopels im Jahre 1204 (wie Anm. 55).

90 P. Magdalino, The Empire of Manuel I Komnenos, 1143-1180. Cambridge 1993, 231; Geanakoplos, Emperor Michael Palaeologus (wie Anm. 1), 43 mit Anm. 57; S. Blöndal, The Varangians of Byzantium. Cambridge 1978, 141-147. Die oft genannte „Varägergarde" (im Sinne einer in dieser Zeit fest etablierten militärischen Einheit) selbst ist wohl ein Phantom der neueren Forschung. Siehe W. Brandes, Das Gold der Menia. Ein Beispiel transkulturellen Wissenstransfers, Millennium 2 (2005) 175-227, hier bes. 217 mit der Anm. 224. 
besseren handschriftlichen Überlieferung im Westen wichtige Rückschlüsse auf die griechischen Textvorlagen möglich sind. Insbesondere der Charakter der 1280 von Michael VIII. verbotenen Schriften - basileiographeia - konnte so näher bestimmt werden. Die hier deutlich werdenden Aspekte eines bisher kaum beachteten Wissenstransfers von Ost nach West hatten eine erhebliche Bedeutung für die Entwicklung der abendländischen Kaisereschatologie.

Doch zurück zu Michael VIII. und seinem Gesetz aus dem Jahr 1280. Georgios Pachymeres schreibt in dem Kapitel seines Geschichtswerkes, an dessen Ende er über das eingangs erwähnte Gesetz berichtet, ausführlich von Verfolgungen gegen zahllose Personen und Personengruppen, insbesondere gegen Mönche. ${ }^{91}$ Auf die Hintergründe kann ich hier nicht ausführlich eingehen. Sie sind bekannt und waren schon mehrfach Gegenstand der Forschung. ${ }^{92}$ Nur soviel sei gesagt: Als Michael VIII. im Jahre 1274 auf dem Konzil von Lyon in eine Kirchenunion mit Rom einwilligte, die u.a. die Anerkennung des päpstlichen Primats, der Lehre vom Fegefeuer und das Filioque-Problem beinhaltete, brach in Byzanz und den anderen Staaten, die sich zur orthodoxen Lehre bekannten (Serbien, Epirus u. a.), ein Sturm der Entrüstung los. Ziel der so umstrittenen Unterwerfung, denn um eine solche handelte es sich zweifellos, ${ }^{93}$ war die Abwehr eines drohenden Angriffs Karls von Anjou gegen das wiedererstandene Byzantinische Reich. Trotz umfangreicher Verfolgungen, in deren Kontext das hier behandelte Gesetz gehört, und der Installation eines unionstreuen Patriarchen (Johannes XI. Bekkos), riß der Widerstand nicht ab und überschattete die letzten Regierungsjahre Michaels. Unter seinem Nachfolger Andronikos II. wurde dann 1285 die Union aufgekündigt. Karl von Anjou, der König von Sizilien, war gestorben, ${ }^{94}$ und die inneren (und äußeren)

91 J. Gill, Byzantium and the Papacy, 1198-1400. New Brunswick 1979, $176 \mathrm{f}$.

92 Siehe u. a. B. Roberg, Die Union zwischen der griechischen und der lateinischen Kirche auf dem II. Konzil von Lyon (1274). Bonn 1964; V. Laurent/J. Darrouzès, Dossier grec de l'Union de Lyon 1273-1277. Paris 1976; J. Gill, The Church Union of the Council of Lyons (1274) Portrayed in Greek Documents, OCP 40 (1974) 5-45; D.M. Nicol, The Byzantine Reaction to the Second Council of Lyons, 1274, Studies in Church History 7 (1971) 113-146; H.-G. Beck, Geschichte der orthodoxen Kirche im byzantinischen Reich (Die Kirche in ihrer Geschichte, I/D1). Göttingen 1980, 200 ff.; B. Roberg, LexMa VI (1993) 47 f. (s.v. II. Konzil von Lyon).

93 Nicht vergessen werden darf, daß Michael ja durch einen Staatsstreich und die Ermordung des legitimen Kaisers Johannes IV. Laskaris zur Alleinherrschaft kam (dazu: G.

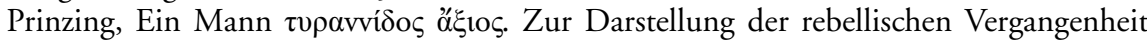
Michaels VIII. Palaiologos, in: Lesarten. Festschrift für Athanasios Kambylis zum 70. Geburtstag ..., hg. von I. Vassis/G.S. Henrich/D.R. Reinsch. New York/Berlin 1998, 180-197). Zu den oppositionellen Anhängern der Laskariden gesellten sich die Arseniten, die Anhänger des auf unkanonische Weise zum Rücktritt gezwungen Patriarchen Arsenios. Siehe u. a. Geanakoplos, Emperor Michael Palaelogus (wie Anm. 1), $264 \mathrm{ff}$.

94 Siehe P. Herde, LexMa V (1991) 983-985 (s.n. Karl I. von Anjou); H. Bresc, LexMa VII (1995) 1948-1950 (s.v. Sizilianische Vesper). 
Widerstände gegen die Union drohten den Staat zu destabilisieren. Bereits 1282 hatte die sog. Sizilianische Vesper die unmittelbare Gefahr aus dem Westen gebannt.

Der kritische Bericht des Georgios Pachymeres läßt deutlich seine Ablehnung der geschilderten Verfolgungsmaßnahmen erkennen. Er nennt eine nicht geringe Anzahl von konkreten Fällen, von denen zwei im hier untersuchten Zusammenhang besonders interessant sind. Ein gewisser Georgios, Sohn eines Pachomios und gelehrter grammatistes, und Michael Strategopulos hielten sich in Herakleia Pontike ${ }^{95}$ auf. Sie machten sich verdächtig, weil sie - tatsächlich oder angeblich - nächtens sog. „kaiserliche Bücher" studierten, wohl um

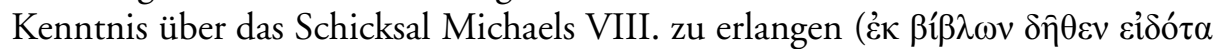
$\beta \alpha \sigma i \lambda \varepsilon(\hat{\omega} v)$. Man denunzierte sie und umgehend erfolgte ihre Verhaftung. ${ }^{96}$ Der Kaiser setzte den Protostrator Michael Strategopulos ab, und man klagte ihn an, die Kaiserherrschaft anzustreben. ${ }^{97}$ Der Kaiser wollte Strategopulos blenden lassen, nahm dann aber davon Abstand, da sich die Kaiserin, seine Cousine, für ihn einsetzte. ${ }^{9}$ Dafür traf der volle Zorn des Kaisers Georgios, den Sohn des Pachomios. Dieser wurde geblendet.

Ähnlich verlief ein Prozeß gegen Ioannes Angelos, den Sohn des Despoten Michael II. Dukas (Angelos), ${ }^{99}$ der wohl auch im Jahre 1280 stattfand. Auch

95 Es ist interessant, daß sich gerade hier, in Herakleia Pontike, einer der vier Orte befand, wo man bis in die Spätantike hinein (vgl. Amm. Marcell. [wie Anm. 11], III, 24 [22.8.16-17] Seyfarth) einen Zugang zur Unterwelt zeigte. Hier, in einem nekumanteion, betrieb man Totenbeschwörungen. Vgl. z. B. Plutarch, Kimon VI und zahlreiche andere antike Texte. Dazu zuletzt D. Ogden, Greek and Roman Necromancy. Princeton/ Oxford 2001, bes. 29 ff. Daß Georgios Pachymeres Plutarch kannte, kann man voraussetzen. Herakleia Pontike war also von vornherein ein übel beleumundeter Ort.

96 Georges Pachymérès, Relations historiques II, ed. Faillier (wie Anm. 4), 615,22-617,11:

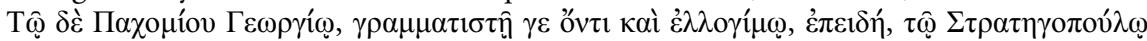

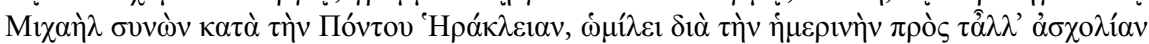

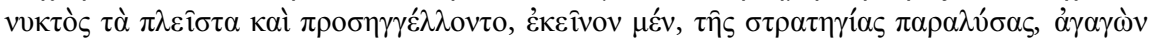

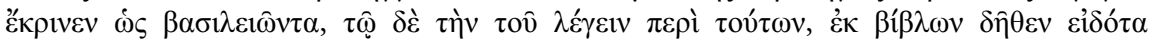

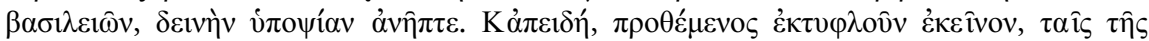

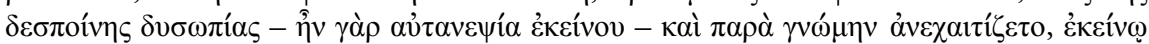

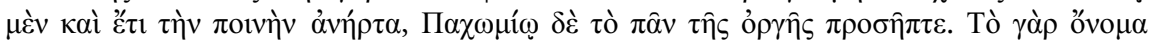

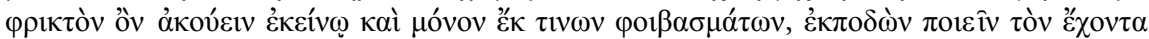

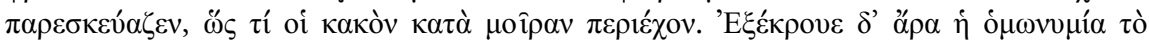

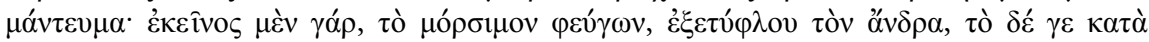

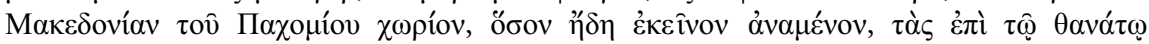

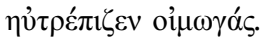

97 Jedenfalls wurde er 1293 erneut des Hochverrats bezichtigt und in einem Schauprozeß in Konstantinopel verurteilt.

98 Siehe zu ihm PLP 26898. Zur Kaiserin siehe A.-M. Talbot, Empress Theodora Palaiologina, Wife of Michael VIII, DOP 46 (1992) 295-303.

99 PLP 205 (Ioannes Angelos); zum Despoten Michael II. von Epiros siehe z. B. Nicol, Last Centuries (wie Anm. 1), 21-32. 
ihm, der wie schon Michael Strategopulos mit den wichtigsten Adelsfamilien verwandt war und schon deshalb als potentieller Usurpator in Frage kam, wurde unterstellt, die Kaiserherrschaft angestrebt zu haben. Als erfolgreicher Feldherr war er außerdem sehr populär. In seinem Prozeß spielte ein Mönch namens Theodoros Kotys ${ }^{100}$ eine verhängnisvolle Rolle. Dieser habe mit Ioannes sehr viel Zeit verbracht, und unter der Folter bekannte er, daß sie sich u.a. um die Kenntnis des zukünftigen Kaisers bemüht hätten (

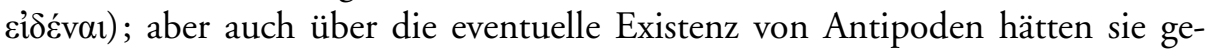
meinsam nachgedacht. ${ }^{101}$ Die Untersuchungen wurden ohne Ansehen der Person brutal geführt. Häufig kam die Folter zum Einsatz. Ioannes Angelos beging schließlich nach seiner Blendung in der Haft Selbstmord.

Die erwähnten Praktiken, das Suchen nach den Lebensdaten des regierenden Kaisers, der ob seiner Union mit dem Papsttum allgemein verhaßt war, und die Hoffnung auf einen neuen Kaiser, der einen Wandel der Politik bewirken würde, wurden offensichtlich besonders in monastischen Kreisen gepflegt. ${ }^{102}$ Dies jedenfalls legt der weitere Bericht des Georgios Pachymeres nahe. „Nunmehr ergriff ihn (nämlich den Kaiser) der Zorn gegen die Mönche, nicht weil sie sich von der Kirche absonderten, sondern weil sie seine Tage zählten und seine Jahre berechneten, hoffend, so eine Erleichterung angesichts der schlechten Gegenwart zu finden. ${ }^{103}$ Auch hier finden wir wieder Versuche, die unmittelbare Zukunft zu erkennen. Natürlich sagt Georgios Pachymeres hier nichts

100 PLP 13346 (Theodoros Kotys); PLP 205 ([Angelos] Ioannes Dukas).

101 Georges Pachymmérès, Relations historiques, II, ed. Failler (wie Anm. 4), 613,9-615,4.

102 Was natürlich nicht bedeutet, daß andere Gruppen der Gesellschaft sich von ihnen fernhielten. Seit der Spätantike gab es kaum einen Kaiser (zumindest kaum einen erfolgreichen Usurpator), der nicht zur Legitimierung seiner Herrschaft eine „Prophezeiung“ eines „heiligen Mannes“, meist eines Mönches, für seine Propaganda nutzte. Siehe

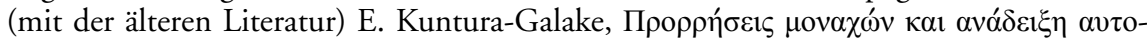

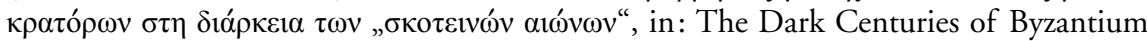
(7th - 9th c.), ed. by W. Kuntura-Galake. Athen 2001, 421-444. Daß Priester und Mönche heftigst gegen Kaiser agitieren konnten, ohne daß dabei „Prophezeiungen“ o. ä. eine Rolle spielten, zeigt das Beispiel des Presbyters Theodoros Rhadenos (PLP 23990), der im Jahre 1315 wegen antikaiserlicher Propaganda vom Patriarchen (Ioannes XIII. Glykys) und der Synode verurteilt wurde. Siehe Das Register des Patriarchs von Konstantinopel, I, hg. von H. Hunger/O. Kresten (CFHB 19/1). Wien 1981, 214-219 (Nr. 19).

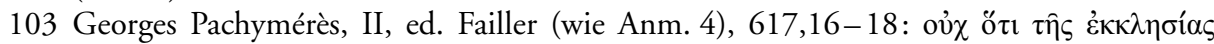

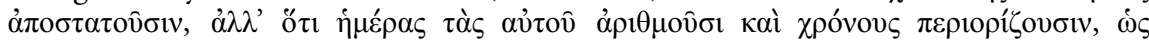

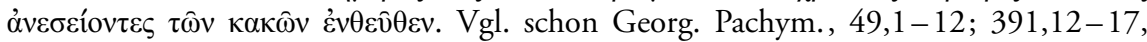
667,11-18 Faillier; ähnliches berichtet schon Nik. Chon. (wie Anm. 39) 221,31-33 van Dieten. Faillier a.a.O. 616 Anm. 2, meinte zwar, daß es sich hier um Berechnungen auf der Basis des Zahlenwertes der Buchstaben des Namens des Kaisers handelte. Das ist durchaus möglich, geht jedoch nicht direkt aus dem Text hervor. Außerdem ergibt der Zahlenwert von Michael keinen Sinn. 
über „kaiserliche Bücher“, basileiographia, und es sind diverse andere mantische oder auch astrologische ${ }^{104}$ Methoden denkbar, die Ioannes und Theodoros anwendeten (etwa Berechnungen auf der Grundlage des Zahlenwertes der Buchstaben bestimmter Namen, wie dies bereits in der Spätantike getrieben wurde ${ }^{105}$ ), doch ist die Wahrscheinlichkeit groß, daß auch sie in Werken der byzantinischen Apokalyptik oder in Schriften, die zur Orakelliteratur zu zählen sind, wie die „Orakel Leons des Weisen“, nach dem begehrten Wissen um die Zukunft des Kaisers suchten. Denn diese, wie auch verschiedene Apokalypsen, boten genug Zahlenmaterial, Angaben von Herrschaftsjahren und diverser prognostizierter Kaiser, die man auf Michael VIII. projizieren konnte. ${ }^{106}$ Die besondere Erwähnung der Mönche als Gegner Michaels, die dessen "Jahre zählten“, ist ein weiteres, wenn auch nicht zwingendes, Argument dafür, hinter diesen Aktivitäten eine Benutzung von Schriften der apokalyptischen Literatur zu sehen. Dies hatte, wie schon gesagt, Tradition in monastischen und kirchlichen Kreisen. ${ }^{107}$

104 Es ist nicht auszuschließen, daß sie über ein Horoskop des Kaisers verfügten, auch wenn sich davon keine Spur erhalten zu haben scheint. Allerdings sind Horoskope bezogen auf den Tag der Krönung der Kaiser Alexios I., Manuel I. und Manuel II. überliefert (s. D. Pingree, Gregory Chioniades and Palaeologan Astronomy, DOP 18 [1964] 133-160, hier 138 mit Anm. 39; Ders., The Astrological School of John Abramius, DOP 25 [1971] 189-215, hier 193). Von Konstantin VII. ist sogar ein Horoskop zum Datum seiner Geburt (3. 9. 905) überliefert. Siehe D. Pingree, The Horoscope of Constantine VII Porphyrogenitus, DOP 27 (1973) 217-231.

105 Siehe oben Anm. 10.

106 Ausgangspunkt derartiger Rechnungen müßten die Herrschaftsdaten Michaels sein: nach dem 1.1.1259 wurde er Mitkaiser; anläßlich seines Einzugs in Konstantinopel am 15.8. 1261 wurde er von dem Patriarchen Arsenios nochmals gekrönt. Dem Endzeitkaiser werden in der Regel in den verschiedenen Apokalypsen 32 Jahre zugestanden, was auf Michael schlecht paßt (vgl. z. B. die „Letzte Vision Daniels“, ed. Schmoldt, Die Schrift [wie Anm. 31], 137 [c. 59]; die „Weissagung Daniels über die letzten Zeiten“, ed. Schmoldt a.a.O., 211 [c. III,12]; die Apokalypse des Andreas Salos, ed. L. Rydén, The Andreas Salos Apocalypse. Greek Text, Translation and Commentary, DOP 28 [1974] 197-261, hier 216; The Life of St Andrew the Fool, ed. by L. Rydén, II. Uppsala 1995, 262 [1.3842]); auch eine andere Tradition, die ihm 12 Jahre zubilligte (nach dem Vorbild Alexanders des Großen), kommt hier nicht in Frage (vgl. u. a. die „Letzte Vision Daniels“ a.a.O., 137 [c. 60]; „Der Mönch Daniel über die Siebenhügelige ...“, ed. Schmoldt a.a.O., 197 [c. 22]; Apokalypse des Andreas Salos a.a.O., 218). Andere Apokalypsen billigen ihm 30 Jahre zu (u. a. „Der Mönch Daniel über die Siebenhügelige ..." a.a.O., 195 [c. 11]; K. Berger, Die griechische Daniel-Diegese. Eine altkirchliche Apokalypse [Studia post-biblica, 27]. Leiden 1976, 69 [c. VI,25]). Wirft man hingegen einen Blick in die handschriftliche Überlieferung, dann wird deutlich, daß sich hier fast alle möglichen Jahresangaben finden lassen. Es ist in methodischer Hinsicht mithin gefährlich, sich allein auf die gedruckten Texte zu verlassen.

107 Siehe schon bei Anm. 91, 102 und 103. 
Ausgehend von der Erkenntnis, daß die unter der Bezeichnung basileiographeion im Jahre 1280 inkriminierten Schriften aller Wahrscheinlichkeit nach zum Genus der Apokalypsen zu zählen sind (wobei besonders an Daniel-Apokalypsen gedacht werden kann), erhebt sich die Frage, ob es sich hier um einen speziellen Einzelfall handelte. Byzanz kannte eine reiche apokalyptische Literatur und zahlreiche Orakel, die erst seit wenigen Jahren intensiver erforscht

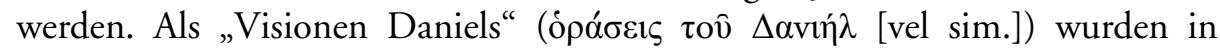
Byzanz Schriften sehr verschiedenen Charakters bezeichnet, die allerdings ein gemeinsames Merkmal aufwiesen: Sie deuteten die Gegenwart und die $\mathrm{Zu}-$ kunft, und dies aus sehr unterschiedlichen Quellen: ${ }^{108}$ aus den Träumen (oneirokritika), ${ }^{109}$ aus dem Donner (Brontologien), ${ }^{110}$ aus Erdbeben (Seismo-

$108 \mathrm{Zu}$ dieser ansonsten kaum behandelten Literatur siehe M.A. Andreeva, Političeskij i obščstvennyi èlement vizantijsko-slavjanskich gadatel'nych knig, BSl 2 (1930) 47-73, $395-415 ; 3$ (1931) 430-461; 4 (1932) 65-84; 5 (1933/1934) 120-161, hier bes. 143-153. Es ist bemerkenswert, daß offenbar Brontologien, Seismologien und vergleichbare Bücher zur „Handbibliothek“ der Kaiser gehörten, wenn sie einen Feldzug unternahmen. Siehe Constantine Porphyrogenitus, Three Treatises on Imperial Military Expeditions. Introduction, edition, translation and commentary by J. Haldon (CFHB

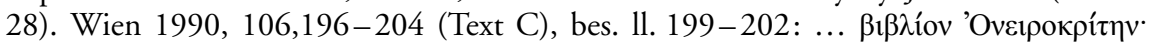

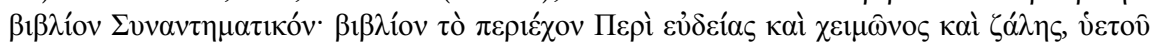

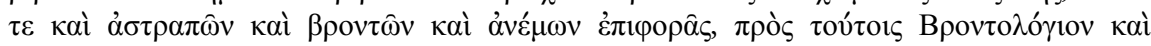

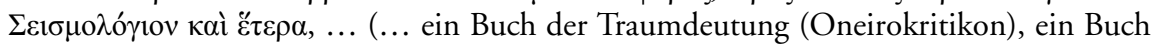
der „Zufälle und Begebenheiten“ [Synantematikon], ein Buch über gutes Wetter und Sturmwetter und Regenguß, Platzregen sowie Blitz und Donner und den Ansturm der Winde [Windstärke], dazu ein „Donnerbuch“ [Brontologion] und ein „Erdbebenbuch“ [Seismologion] und andere [scil. Bücher] ...). Zu den verschiedenen mantischen

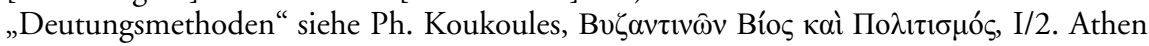
1948, 155-226; vgl. auch P. Lemerle, Le testament d'Eustathios Boilas (Avril 1059), in: Ders., Cinq études sur le XI ${ }^{\text {e }}$ siècle. Paris 1977, 15-63, hier 25 (Z. 160). Siehe jetzt auch DiTommaso, The Book of Daniel (wie Anm. 31).

109 F. Drexl, Das Traumbuch des Propheten Daniel nach dem cod. Vatic. Palat. gr. 319, BZ

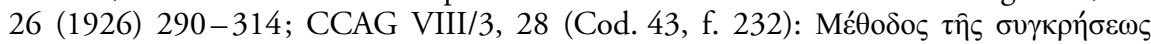

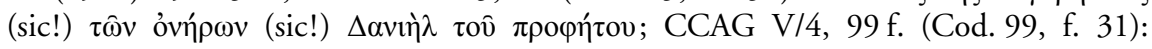

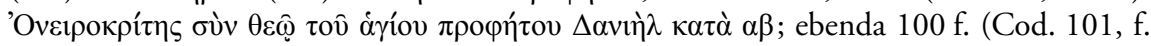
146r, ed. CCAG VIII/3, 172,16-28); CCAG VII, 33 (Cod. 17, f. 4v): 'Ovєıрокрıєıко̀v

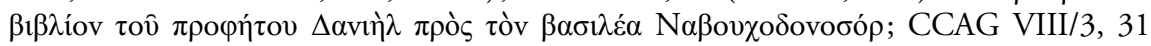
(Cod. 43, f. 239); CCAG XII, 24 (Cod. 3, f. 132); vgl. jetzt die ausgezeichnete Monographie von M. Mavroudi, A Byzantine Book on Dream Interpretation. The Oneirocriticon of Achmet and Its Arabic Sources (The Medieval Mediterranean, 36). Leiden/ Boston/Köln 2002; K. Brackertz, Die Volks-Traumbücher des byzantinischen Mittelalters. München 1993.

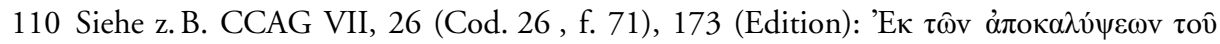

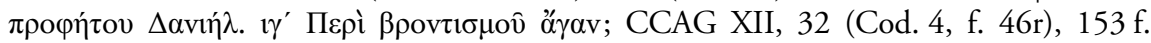
(Edition); CCAG VII, 171; CCAG IX/1, 77 (Cod. 33, f. 1); CCAG IX/2, 42 (Cod. 58, f. 89). Zu den Brontologien siehe allgemein F.R. Trombley/A. Kazhdan, ODB 326. 
logien), ${ }^{111}$ aus metereologischen Phänomenen, ${ }^{112}$ aus der Physiognomik relevanter Personen (physiognomikon), ${ }^{113}$ aus „Würfelorakeln ${ }^{\text {“114 }}$ oder aus astrologisch-astronomischen „Künsten “ ${ }^{\text {"15 }}$ und - natürlich - in Form von Offenbarungen, Apokalypsen nach dem Vorbild des alttestamentarischen Danielbuches. Sie alle konnten „Visionen Daniels“ heißen, eine Bezeichnung, die man sonst gemeinhin für die apokryphen Apokalypsen reservierte. Ähnlich verhält es sich mit Leon VI., dem „Weisen“, ${ }^{116}$ unter dessen Namen die verschiedensten

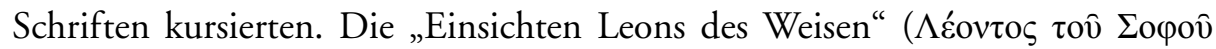
$\gamma v \hat{\mu} \mu \alpha \imath)$ z.B. bieten die eigenartigsten Berechnungen, deren Sinn sich kaum erschließt. ${ }^{117}$ Es sei denn, sie dienen dem Verständnis des in einigen Handschriften folgenden Textes, einer „Psephos diagnostike des Lebens und des Todes

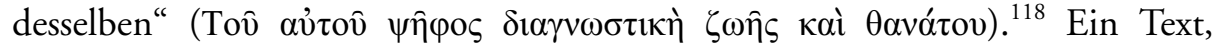

111 CCAG VII, 47 (Cod., f. 137v); CCAG X, 24 (Cod. 10, f. 37v); CCAG XII, Cod. 4, Cod. bibl. publicae Petropol. 575 (s. XVII), fol. 46r/v; vgl. die Ausführungen von Weinstock in CCAG V/4, $155 \mathrm{f}$.

112 Siehe z.B CCAG VII, 47 (Cod. 25, f. 137v, 138r), 50 f. (Cod. 26, f. 69r), 171 f. Edition:

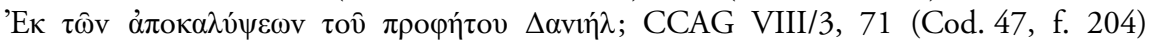

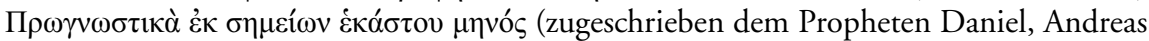
Salos, Papst Hippolyt); CCAG VIII/4, 8 (Cod. 67), 84 (Cod. 113, f. 19); CCAG X, 28

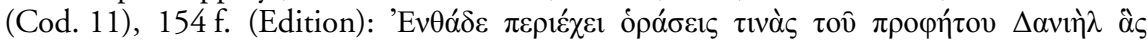

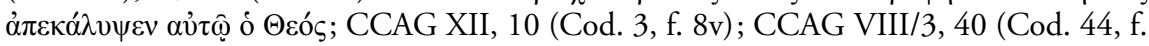
380v), 173-179 (Edition).

113 CCAG XII, 24 (Cod. 3, . 147v).

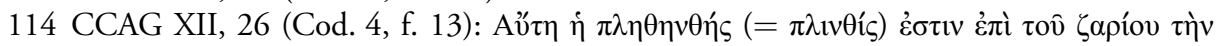

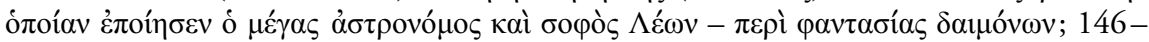
151 (Edition); zu den „Würfelorakeln“ siehe Au. Mau, RE II/2 (1896) 1793 (s.v. Astragalomanteia).

115 CCAG V/4, p. 100 (Cod. 10, f. 146-321); CCAG V/4, 100 (Cod. 101,); CCAG VI, 4 (Cod. 2); CCAG VIII/3, 40 (Cod. 44; f. 380v), 172-179 (Edition der 25 Kapitel dieses astrologisch-astronomischen Textes; siehe auch D. Pingree, From Astral Omens to Astrology from Babylon to Bīkāner. Rom 1997, 76); auch in CCAG IX/1, 79 (Cod. 33, f. 18), 82 (Cod. 60, f. 30 ff.); CCAG VIII/3, 82 (Cod. 60, f. 30) ; CCAG VIII/4, 8 (Cod. 67, f. 305v; CCAG VIII/3, 171,4-174,5), 84 (Cod. 113, f. 19); CCAG VII, 171 ff.; CCAG XII, 153-155; CCAG X, 28 (Cod. 11, f. 25v), 154-155 (Edition):

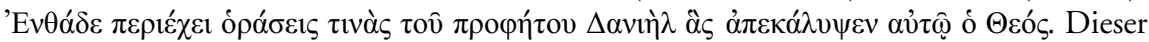
Text (oder Teile desselben) auch in CCAG III, 12 (Cod. 15, f. 1); CCAG VII, 47 (Cod. 25, f. 137v), 50 (Cod. 26, f. 69); CCAG VIII/3, 40 (Cod. 44, f. 380v), 71 (Cod. 47, f. 204).

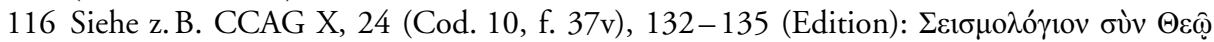

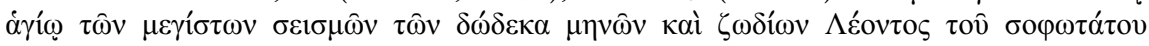
$\beta \alpha \sigma i \lambda \varepsilon \dot{\varepsilon} \omega$.

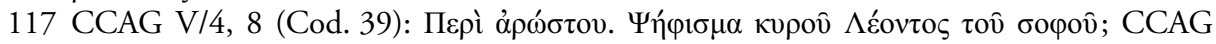

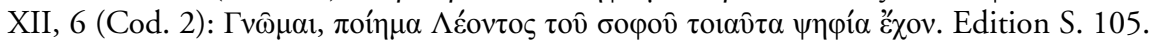

118 CCAG IV, 35 (Cod. 13, f. 263); vgl. CCAG VI, 35 (Cod. 3, f. 122v) (vgl. H. Hunger, Katalog der griechischen Handschriften der Österreichischen Nationalbibliothek, I. Wien 1961, 287); CCAG XII, 6 (Cod. 2, f. 65v). 
ebenfalls Leon zugeschrieben, ist von besonderem Interesse, gibt er doch Anweisungen, wie man zukünftige Kaiser und „Archonten“, ihre Regierungszeit

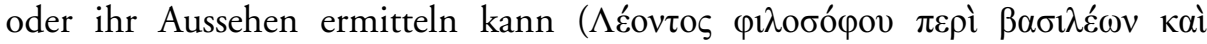

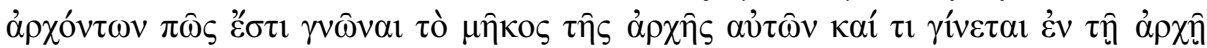

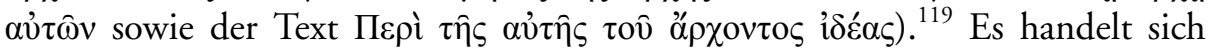
hierbei tatsächlich um eine Art Anleitung, um mit astrologischen Mitteln u.a. die Regierungszeiten zukünftiger Kaiser zu ermitteln, oder den Charakter (gut oder schlecht) ihrer Herrschaft. Auch eine Anleitung zur Erforschung der $\mathrm{Zu}$ kunft mittels der „Befragung“ der Heiligen Schrift wurde ihm zugeschrieben. ${ }^{120}$

Was bisher kaum thematisiert wurde, ist der "Sitz im Leben“ dieser Literatur bzw. des Denkens, das sie repräsentierte. ${ }^{121}$ Michaels VIII. Gesetz aus dem Jahre 1280 bietet einen Anlaß, darüber nachzudenken. Deshalb seien hier einige wenige Beispiele angeführt, deren Anzahl sich leicht vermehren ließe.

\section{III}

Während der zweiten Phase des sog. Bilderstreites, in der ersten Hälfte des 9. Jhs. ${ }^{122}$ kam es zu einigen erstaunlichen Vorgängen, die in die Vorgeschichte der eben geschilderten Ereignisse aus dem ausgehenden 13. Jh. einzuordnen sind. ${ }^{123}$ Der spätere Patriarch von Konstantinopel, der bis heute als Heiliger verehrte Methodios, verfaßte die Vita seines Mitkämpfers gegen den Ikonoklasmus, Euthymios von Sardes. ${ }^{124}$ Diese Vita weist, wie schon ihr Editor Jean Gouillard

119 Ediert CCAG IV, 92-93, vgl. ebenda 14 (Cod. 4); CCAG II, 22 (Cod. 6), 52 (Cod. 7); CCAG V/4, 86 f. (Cod. 98).

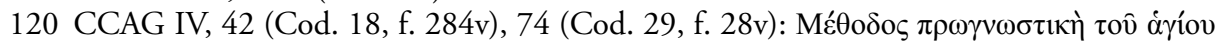

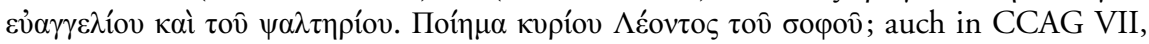
33 (Cod. 17, f.1); CCAG XI/1, 111 (Cod. 12, f. 44).

121 W. Brandes, Endzeitvorstellungen und Lebenstrost in mittelbyzantinischer Zeit (7.-

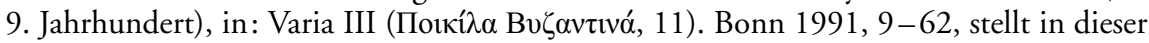
Hinsicht einen eher ungenügenden Beginn dar.

122 Siehe P. Schreiner, Der byzantinische Bilderstreit: kritische Analyse der zeitgenössischen Meinungen und das Urteil der Nachwelt bis heute, Sett. 34 (1988) 319-407; W.T. Treadgold, The Byzantine Revival, 780-842. Stanford 1988.

123 Die „Prosopographie der mittelbyzantinischen Zeit“ übergeht seltsamerweise diese Episode. Siehe PmbZ 1338 (Euthymios von Sardeis); 3448 (Joseph von Thessalonike) und 4977 (Methodios). B. Zielke, Methodios I., in: Die Patriarchen der ikonoklastischen Zeit, hg. von R.-J. Lilie (BBS 5). Frankfurt am Main 1999, 212 f. äußerte unberechtigte Zweifel an der überlieferten Geschichte.

124 Siehe R. Gouillard, La vie d'Euthyme de Sardes († 831) une oeuvre du patriarche Méthode, TM 10 (1987) cap. 13-14 (p. 41 ff.); siehe auch Dens., Une oeuvre inédite du patriarche Méthode: La vie d'Euthyme de Sardes, BZ 53 (1960) 36-46; dazu zuletzt (wenn auch unzureichend) D.E. Afinogenov, Iconoclasm and Ecclesiastical Freedom: Two Approaches in Ninth-Century Byzantium, in: The Christian East. Its Institutions 
betonte, zahlreiche autobiographische Züge auf. ${ }^{125}$ Sie hat mithin als erstrangige Quelle zu gelten. Methodios selbst, Euthymios und Joseph, der Erzbischof von Thessalonike (Bruder des berühmten Theodoros Studites), agierten gemeinsam gegen die verschiedenen Kaiser dieser Zeit (Leon V. [813-820], Michael II. [820-829] und Theophilos [829-842]), die sich gegen den Bilderkult entschieden hatten. Methodios teilte mit, daß seine Verhaftung und der Vorwurf des Hochverrats, den Kaiser Theophilos gegen ihn erhob, auf folgenden Vorkommnissen basierten: Es sei eine ,anzeigende, denunziatorische, verräterische

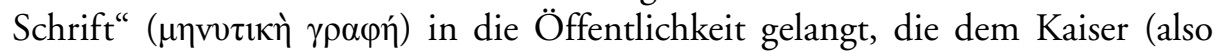
Theophilos) seinen nahen Untergang verkünde - so wie bereits eine andere derartige Schrift acht Monate vor seiner Ermordung Kaiser Leon (V.; $† 25.12$. 820) ${ }^{126}$ den Tod prophezeit habe. Gleiches geschah dann mit Michael II., dessen Tod ihm fünf Monate vor seinem tatsächlichen Ableben († 2.10. 829) vorausgesagt wurde. ${ }^{127}$

Und nun wurde auch Theophilos der baldige Tod vorausgesagt. Da die erste und die zweite Weissagung (ungefähr) eingetroffen waren, hegte man nun auch keinen Zweifel an der Richtigkeit der dritten. Anders als seine Vorgänger reagierte Kaiser Theophilos konsequent und durchgreifend. Er ließ die drei Hauptverdächtigen - Euthymios von Sardes, Joseph von Thessalonike sowie den späteren Patriarchen Methodios - verhaften. Bei den scharfen Verhören kam Euthymios, hochbetagt, zu Tode, was ihm einen Platz im orthodoxen Heiligenkalender sicherte. ${ }^{28}$

Methodios selbst gab in seiner Vita des Euthymios zu, daß man ihm von kaiserlicher Seite zwei der drei erwähnten apokalyptischen Kampfschriften zuschrieb, nämlich diejenigen, die den Tod Leons V. und Michaels II. voraussagten. Er bestreitet dies keineswegs, und seine Schilderung macht fast den Eindruck, als sei er sogar etwas stolz, was schon Gouillard auffiel. Die dritte Weissagung, gegen Theophilos gerichtet, stammte aber vermutlich nicht von Methodios, denn dieser weilte zum Zeitpunkt der Abfassung der dritten anti-

and Its Thought. A Critical Reflection, ed. R.F. Taft (OCA 251). Rom 1996, 591-611, hier 602.

125 Siehe Gouillard, TM 10 (1987) 14.

$126 \mathrm{Zu}$ den dramatischen Vorgängen bei der Ermordung Leons V. siehe die Angaben in der PmbZ 4244; Treadgold, Revival (wie Anm. 122), 223-225.

$127 \mathrm{Zu}$ Michael II. siehe die PmbZ 4990. Siehe auch den bei Pertusi, Fine di Bisanzio (wie Anm. 27), 162-166 edierten Text (Logoi des Philosophen Brysos über die letzten Zeiten; nach einer kalabresischen Hs. des 10. Jhs.): Der Beginn des Schlechten auf der Erde wird kommen, wenn der Drache aus Babylon herrschen wird; er ist völlig unfähig zu sprechen, jedoch im höchsten Maße geldgierig usw. Nach Pertusi a.a.O. reflektiert der Text in apokalyptischer Form das Vordringen der Araber in Sizilien z.Z. der Herrschaft Michaels II.

128 Zum Tod des Euthymios siehe auch die Acta ss. Davidis, Symeonis et Georgii Mitylenae in insula Lesbo (BHG 494), ed. I. van den Gheyn, AB 18 (1899) 238. 
kaiserlichen Schrift in Italien. Es waren also wohl Joseph und Euthymios, die, dem Vorbild des Methodios folgend, einen apokalyptischen Traktat gegen Kaiser Theophilos verfaßten und in Umlauf brachten. Das harte Vorgehen gegen Euthymios erklärt sich vermutlich genau aus diesem Umstand. Es wurde vermutet, daß es sich bei dem zweiten Traktat, der gegen Michael II. gerichtet war, um die griechische Vorlage der nur altslawisch überlieferten Daniel-Apokalypse handelte. ${ }^{129}$ Dies ist durchaus möglich, zumal die Apokalypse eindeutig mit Michael II. endet. ${ }^{130}$ Allerdings sollte man nicht davon ausgehen, daß dieses apokalyptische „Flugblatt“, wie man etwas modernisierend sagen könnte, wirklich genau dieser Daniel-Apokalypse entsprach. Es dürfte sich um eine Kurzfassung gehandelt haben und nicht um die vollständige Apokalypse, die ein gutes Dutzend Druckseiten füllt.

Es handelte sich also nicht unbedingt in erster Linie um Maßnahmen des Kaisers Theophilos wegen des fortdauernden religiösen Widerstandes der drei Inkriminierten, es ging vielmehr um politische Agitation und um Angriffe gegen die kaiserliche Autorität selbst. Mit dem sog. Bilderstreit, in dessen Kontext die Verfolgungen von Euthymios, Joseph und Methodios bisher meist gesehen wurden, hatte die Affäre nur insofern zu tun, als hier ikonophile Gegner der gegen die Bilder gerichteten kaiserlichen Politik zu einem höchst gefährlichen Mittel griffen, um ihre theologischen Positionen duchzusetzen. Daß sie sich dabei - ob bewußt oder unbewußt - dem aus staatlicher Sicht berechtigten Verdacht des Hochverrats aussetzten, ist vielleicht sogar einem Wunsch nach dem Martyrium geschuldet.

Die erhebliche Relevanz derartiger Schriften erhellt auch eine Geschichte, die ebenfalls aus dem 9. Jh. stammt und erhebliche Spuren in der mittelbyzantinischen Historiographie hinterließ: Kaiser Leon V. habe in der kaiserlichen Bibliothek ein Buch mit „sibyllinischen Weissagungen“ über die zukünftigen Kaiser des Byzantinischen Reiches gefunden, das „große Schrecken in seine Seele brachte “. ${ }^{131}$ Der sog. Theophanes Continuatus berichtet, ${ }^{132}$ daß Leon V. in

129 Treadgold, Revival (wie Anm. 122), 276 f.; siehe jetzt auch W.T. Treadgold, The Prophecies of the Patriarch Methodius, REB 62 (2004) 229-237.

130 Alexander, Apocalyptic Tradition (wie Anm. 27), 65-72; Pertusi, Fine di Bisanzio (wie Anm. 27), 81-89.

131 Einige der einschlägigen Texte wurden schon von Lambeck in seiner Ausgabe der Oracula Leonis zusammengestellt (P. Lambeck, Leonis imperatoris cognomine Sapientis oracula, in calce a Gregorii Codini excerpta de Antiquitatibus Constantinopolitanis. Paris 1655); siehe PG 107, 1124; Mango, ZVRI 6 (1960) 62 f.; Vereecken/HadermannMisguich, Les Oracles de Léon le Sage (wie Anm. 60), 20 mit Anm. 4; siehe auch die folgende Anm.

132 Theophanes Continuatus, Ioannes Cameniata, Symeon Magister, Georgius Monachus, rec. I. Bekker. Bonn 1838, 35,20 -36,11 (cap. I.22); vgl. auch Ioannis Scylitzae Synopsis historiarum, rec. I. Thurn (CFHB 5). Berlin 1973, 20,60-72, der Theophanes Continuatus nahezu wörtlich folgt. Siehe jetzt auch Jean Skylitzès, Empereurs de Constan- 
„einem chresmologion“ die Nachricht entdeckte, daß „am Tage von Christi

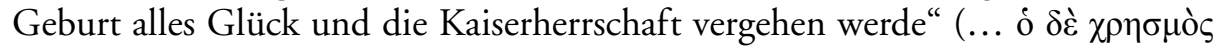

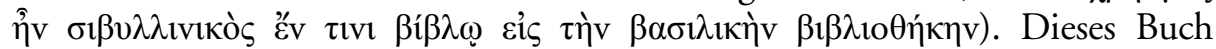
enthielt nicht nur simple Weissagungen, sondern auch kolorierte bildliche Darstellungen ( Löwe war abgebildet, „mit dem Buchstaben Chi über dem Rücken bis zum Bauch" und „durch das Chi hindurch rammt ein Mann einen Pfahl in das Tier“. Viele wurden befragt, was dies wohl bedeuten möge. Der damalige Quaestor, angeblich ein weiser Mann, sagte klar und deutlich, daß diese bebilderte Weissagung besage, daß ein Kaiser namens Leon am Tag der Geburt Christi dem Tod überliefert werden würde.

Eine etwas andere Version bietet Genesios. ${ }^{133}$ „Es war ihm (Leon V.) nämlich die Zeit seiner Ermordung aus einem Orakelbuch geoffenbart worden, das geheimnisvoll andeutete, daß zwischen den Buchstaben Chi und Phi die Kehle eines wilden Löwen mit dem Schwert durchbohrt werden würde, d.h., daß zwischen Christi Geburt und dem Fest ton photon Leon selbst, der das Wesen eines wilden Tieres hatte, ermordet werden würde." Diese Prophezeiung

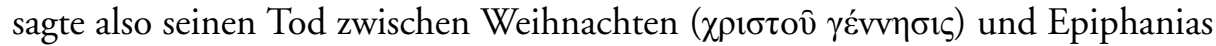
$(\tau \grave{\alpha} \Phi \omega ́ \tau \alpha)$ voraus. Tatsächlich wurde Leon am 25.12. $820 \mathrm{am}$ Altar der Hagia Sophia ermordet.

Die Quellen, die diese Geschichte berichten, sind nicht zeitgenössisch, so daß man zweifellos von vaticinia ex eventu ausgehen muß. Immerhin weist die Abbildung zu einem der „Orakel Leons des Weisen“ aus dem 12. Jh. eine verblüffende Ähnlichkeit mit dem beschriebenen Bild aus der kaiserlichen Bibliothek auf. ${ }^{134}$ Aus dem 14. Jh. berichtet Nikephoros Gregoras über ein ähnliches Buch im Besitz des Kaisers Andronikos' II. (1282-1328). ${ }^{135}$

tinople. Texte traduit par B. Flusin et annoté par J.-Cl. Cheynet (Réalités Byzantines, 8). Paris 2003, 21 mit Anm. 23.

133 Iosephi Genesii regum libri quattuor, rec. A. Lesmueller-Werner/I. Thurn (CFHB 14). Berlin/New York 1978, 16,94-17,3; vgl. Byzanz am Vorabend neuer Größe. Überwindung des Bilderstreites und der innenpolitischen Schwäche (813-886). Die vier Bücher der Kaisergeschichte des Ioseph Genesios. Übersetzt, eingeleitet und erklärt von A. Lesmüller-Werner (Byzantinische Geschichtsschreiber, 18). Wien 1989, 43 f.; vgl. noch Ioannis Scylitzae Synopsis historiarum, rec. I. Thurn (CFHB 5). Berlin 1973, 331,6-13; Pseudo-Symeon, in: Theophanes Continuatus (wie Anm. 132), 610,17611,2 (hier wird der Quaestor Stephanos Kapetolites genannt; siehe PmbZ 7074, 11488).

134 Vereecken/Hadermann-Misguich, Les Oracles de Léon le Sage (wie Anm. 60), 40, 42; Mango, ZRVI 6 (1960) passim; siehe auch J. Signes Codoñer, El periodo del segundo iconoclasmo en Theophanes Continuatus. Análisi y comentario del los tres primeros libros de la crónica (Classical and Byzantine Monographs, 33). Amsterdam 1995, 159 ff., zu den Visionen u. ä. allgemein S. 162 ff.; vgl. die Abbildungen bei A. Rigo, Oracula Leonis. Padova 1988, 82 und Mango a.a.O. Abb. 9 (im Anhang) zu den entsprechenden Abbildungen der Orakel Leons des Weisen; dazu siehe auch The Oracles of 
Zurück ins 12. Jh.: Das Jahr 1159 war für Kaiser Manuel I. eines der schwierigsten seiner langen Regierungszeit $(1143-1180),{ }^{136}$ sieht man einmal von der vernichtenden Niederlage ab, die er am 17. September 1176 in der wichtigen Schlacht von Myriokephalon gegen die Seldschuken ${ }^{137}$ hinnehmen mußte.

Ende 1158 zog Manuel nach Kilikien und Nordsyrien, um die dortigen Verhältnisse in seinem Sinne zu ordnen (Thoros II. von Kleinarmenien sollte aus den kilikischen Städten vertrieben werden; Rainald von Châtillon sollte die byzantinische Oberherrschaft über Antiocheia anerkennen; Nur ad-Din von Aleppo sollte bekämpft werden). ${ }^{138}$

Während der Kaiser weit entfernt von der Hauptstadt weilte, scheint dort eine Verschwörung allmählich Gestalt angenommen zu haben. ${ }^{139}$ Den wichtigsten Quellen zu diesem Vorkommnis kann man entnehmen, daß Theodoros

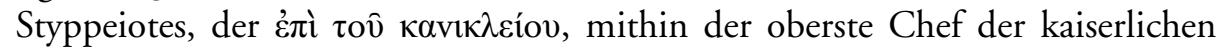
Kanzlei, der durch eine erstaunliche Mischung aus Fachkompetenz und erfolgreichen Intrigen eine einzigartige Machtposition am Hofe Manuels erlangt hatte, plante, dessen Abwesenheit von der Machtzentrale auszunutzen und selbst die Macht zu ergreifen. Rahewin, der Fortsetzer der „Gesta Friderici“ Ottos von Freising, ${ }^{140}$ berichtet, daß drei Mörder gedungen worden seien, die den Kaiser beseitigen sollten.

the Most Wise Emperor Leo, ed. Brokkaar (wie Anm. 60), Plate 10; PG 107, 115, fig. 1155.

135 Nicephori Gregorae Byzantine historia, cura L. Schopeni, I. Bonn 1829, 463; vgl. auch die deutsche Übersetzung Nikephoros Gregoras, Rhomäische Geschichte, übersetzt und erläutert von J.-L. van Dieten (Bibliothek der griechischen Literatur, 9). Stuttgart 1979, 241. Dazu ist Mango, ZRVI 6 (1960) 65 f. zu vergleichen. Alice-Mary Talbot (ODB 94) charakterisierte Andronikos II. als „superstitious“.

$136 \mathrm{Zu}$ ihm siehe das Standardwerk von Magdalino, The Empire of Manuel I (wie Anm. 90).

137 C. Foss, ODB $1429 \mathrm{f}$.

138 Zum historischen Hintergrund siehe R.J. Lilie, Byzanz und die Kreuzzüge. Stuttgart 2004, 111-114 und besonders Magdalino, The Empire of Manuel I (wie Anm. 90), $198-200$.

139 Zum folgenden siehe insbes. O. Kresten, Zum Sturz des Theodoros Styppeiotes, JÖB 27 (1978) 49-103; vgl. außerdem P. Magdalino, Aspects of Twelfth-Century Byzantine Kaiserkritik, Spec. 58 (1983) 326-346, bes. $333 \mathrm{ff}$.

140 Bischof Otto von Freising und Rahewin, Die Taten Friedrichs, oder richtiger Cronica, übers. von A. Schmidt, hg. Von F.-J. Schmale, mit einem Nachtrag von F. Schwarzbauer (Ausgewählte Quellen zur deutschen Geschichte des Mittelalters, 17). Darmstadt ${ }^{4} 2000$, 506/508: Circa idem tempus Manuele Constantinopolitano imperatore circa partes Antiochie contra Turcos cum exercitu morante, unus de servis palatii, caniclinus videlicet, quem nos cancellarium dicere possumus, principi suo fraudem molitus est. Tres siquidem audacissime temeritatis iuvenes infinita corruptos pecunia ad occidendum imperatorem pellexerat, 
Von besonderer Bedeutung sind die Berichte des Niketas Choniates und des Ioannes Kinnamos, die in wesentlichen Punkten voneinander abweichen, zumindest was das eigentliche Vergehen des Theodoros Styppeiotes und des Michael Glykas angeht, auf den gleich zurückzukommen sein wird. Otto Kresten hat in einer Untersuchung ${ }^{141}$ die Fragen der Chronologie und der tatsächlichen historischen Abläufe dieser Verschwörung geklärt. Es bleibt jedoch noch ein wesentliches Element der Vorwürfe gegen Theodoros näher zu spezifizieren. „Er sagte nämlich vielen voraus, gleichsam wie von einem Dreifuß ( $\dot{\omega} \varsigma$ ả $\pi$ ò $\tau \rho i ́ \pi o \delta o \varsigma$ $\dot{\alpha} \pi \varepsilon \varphi \operatorname{ií} \beta \alpha \zeta \varepsilon)$, daß die Lebenszeit des Kaisers bereits gemessen sei. Der Senat müsse die Herrschaft an jemanden übertragen, der kein Jüngling (neanias) voller Stolz sei, sondern an einen bejahrten, erfahrenen Mann. "142 Natürlich hat man diesen Bericht über die „Weissagungen“ des Theodoros Styppeiotes längst in einen Zusammenhang mit der Vielzahl von Prophetien und allen möglichen Weissagungen, die am Kaiserhof der Komnenenzeit zirkulierten, gesehen. Auch die Beschäftigung Kaiser Manuels I. mit Astrologie ist bekannt. ${ }^{143}$ Und doch

ipseque statua die, quando id facinus patrari debuerat, ad occupandum aput urbem simul cum imperiali palatio imperium magnis instructus copiis prestolabatur. Tantum regis periculum cum imperatrici per occultum indicem revelatum fuisset, illa magnitudine sceleris perterrita quam velocissime marito proditionem significat; sicque detecto dolo, comprehensis sicariis, prevento criminis auctore et capto, de omnibus condigna sumuntur supplicia. Caniclinus etenim, primo effossis oculis, lingua perforato gutturi transmissa, sine miseratione miserabili vitam finivit (III,58-59).

141 Kresten, JÖB 27 (1978) 49-103.

142 Ioannis Cinnami epitome rerum ab Ioanne et Alexio Comnenis gestarum, rec. A.

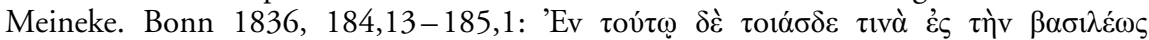

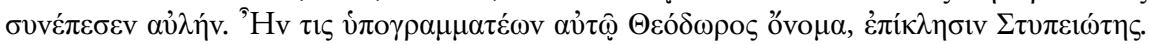

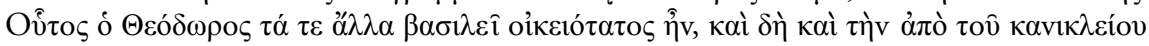

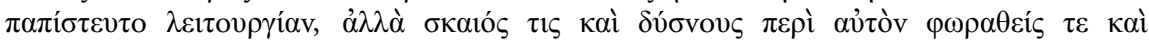

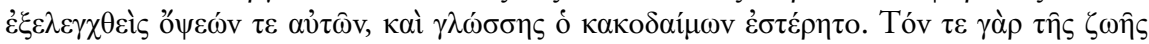

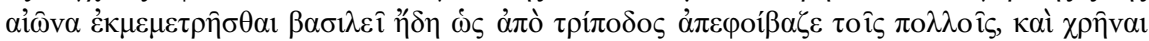

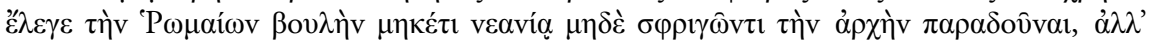

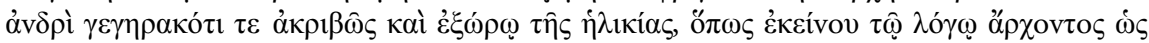

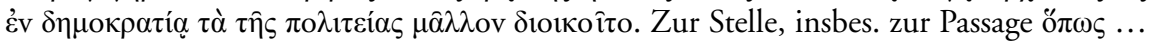

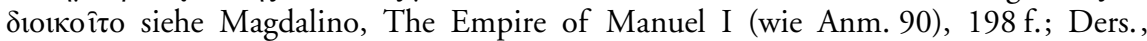
Saec. 58 (1983) 333 f.; Kresten, JÖB 27 (1978) 57. Siehe auch die englische Übersetzung Deeds of John and Manuel Comnenus by John Kinnamos, transl. by Ch.M. Brand. New York 1976, $140 \mathrm{f}$.

143 Siehe Magdalino, The Empire of Manuel I (wie Anm. 90), 200 (Hinweis auf die Orakel Leons des Weisen, die AIMA-Prophetie, die mit dem 3. Orakel Leons des Weisen zusammenhängt [vgl. Nik. Chon. [wie Anm. 39], 146, 169 van Dieten; dazu Mango, ZRVI 6 [1960] 63; C. Varzos, La politique dynastique des Comnènes et des Anges, le prédiction AIMA [sang] et l'héritage des Grands Comnènes de Trébizonde et de AngesComnènes-Doukas d'Epire face aux Lascarides de Nicée, JÖB 32/2 [1982] 355-360), 378 (Manuel und die Astrologie und andere Geheimwissenschaften); vgl. schon Kresten, JÖB 27 (1978) 57, 72, 74. Siehe auch das Manuel zugeschriebene astrologische Werk bei F. Cumont/F. Boll, CCAG V/1, 108-125; vgl. Magdalino a.a.O. 377 ff. Zur Rolle von 
sind drei Aspekte zu beachten, die auch in diesem Fall eine Verwendung apokalyptischer Schriften bzw. der mit ihnen verwandten Kaiserorakel wahrscheinlich machen. Einzeln gesehen, mögen diese Beobachtungen nicht aussagekräftig genug sein, in der Zusammenschau jedoch stützen sie sich gegenseitig.

Die von Ioannes Kinnamos überlieferte Forderung nach einem neuen Kaiser, der kein Jüngling sein sollte, erscheint eigenartig. Manuel wurde am 28.11. 1118 geboren, war also zum Zeitpunkt der Prophezeiung bereits 41 Jahre

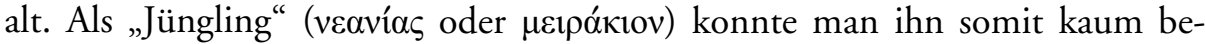
zeichnen. Das Argument der Verschwörer, man müsse nunmehr einen älteren, abgeklärten (weniger aktiven) Kaiser zum Nachfolger machen, mußte Manuel beunruhigen. Aus heutiger Sicht ist diese Forderung überraschend, denn ein erfahrener und über eine gewisse Lebenserfahrung und Kenntnisse der praktischen Politik verfügender Kaiser wie Manuel sollte doch jedem Staatswesen zum Vorteil gereichen. Die brutale Reaktion des Kaisers mußte jedoch noch andere Beweggründe gehabt haben, die sich nicht (allein) aus dem Vorwurf ergaben, er handele wie ein unbedachter Jüngling. Tatsächlich hatte Manuel wohl zu Beginn seiner Regierung (1143) mit der Kritik an seiner Jugend zu kämpfen gehabt. ${ }^{144}$

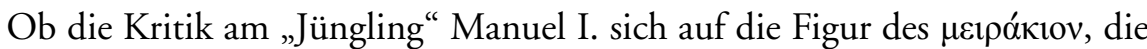
in zahlreichen byzantinischen Apokalypsen ihr Unwesen treibt, beziehen läßt, sei dahingestellt. Es ist auf jeden Fall möglich. ${ }^{145}$ Die „Vision Daniels über die

Prophetien usw. für die Kaiser der komnenischen Dynastie und ihren Nachfolgern (Angeloi) siehe auch das von L. Oeconomos, La vie religieuse de l'Empire byzantin au temps des Comnènes et des Anges. Paris 1918, 65 ff., zusammengestellte Material.

$144 \mathrm{Vgl}$. Magdalino, The Empire of Manuel I (wie Anm. 90), 334; siehe auch den sog. Manganeios Prodromos Nr. 24 (nach Magdalinos Zählung, aus dem Jahre 1147 [ed. E. Miller, Recueil des historiens des croisades. Historiens grecs, II. Paris 1875, $94 \mathrm{f.]}$ )

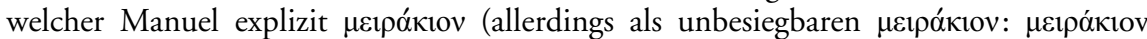

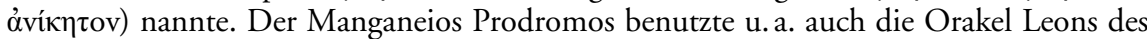
Weisen, wie Magdalino a.a.O. 447 gezeigt hat. $\mathrm{Zu}$ den byzantinischen Vorstellungen

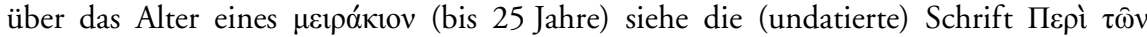

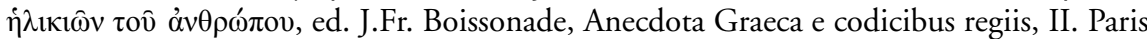
1830 (Nachdruck Hildesheim 1962), 454-457.

145 Siehe die armenische Daniel-Apokalypse, trad. Kalemkiar (wie Anm. 88), 237; AndreasSalos-Apokalypse, ed. Rydén (wie Anm. 106), 219 (= The Life of St Andrew the Fool [wie Anm. 106], II, 268 Rydén) (hier allerdings drei davon). In der „Letzten Vision Daniels" wird er mit Alexios IV. Angelos identifiziert (siehe schon oben Anm. 70); die

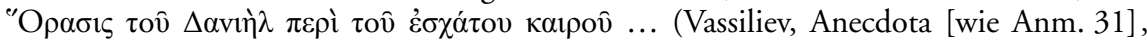
38-43; Schmoldt, Die Schrift [wie Anm. 31], 202-218) beginnt mit dem Wehruf wegen des meirakion; derartige Stellen lassen sich noch weitere finden. Dem widerspricht nicht, wenn Nikephoros Chrysoberges (siehe zu ihm Kazhdan, ODB 451) am 6.1. 1204 (so der Text, doch Brand [siehe gleich], 475 meint mit guten Gründen, daß sie nie öffentlich gehalten wurde) eben dem in apokalyptischer Sicht (allerdings lange nach 1204) so verhängnisvollen Alexios IV. Angelos eine Lobrede präsentierte, die im Preis seiner Jugend (u.a. Vergleiche mit dem jungen David oder Alexander dem Großen) 
letzten Zeiten“ - um nur ein Beispiel von vielen zu zitieren -, die in der bisherigen Forschung meist ins 9. Jh. datiert wird, ${ }^{146}$ beginnt bezeichnend mit dem Wehruf, bezogen auf Konstantinopel und den bevorstehenden Untergang der byzantinischen Hauptstadt, „und in den letzten Tagen wird ein Jüngling (meirakion) aufstehen usw." Mit ihm nimmt das Unglück, das Ende Konstantinopels und der Welt, seinen Anfang. ${ }^{147}$

Ein weiterer, zugegeben nicht zwingender, Umstand, der auf eine Bekanntschaft des Theodoros Styppeiotes mit apokalyptischen Schriften deutet, basiert auf einer Annahme von Kresten und Kazhdan. ${ }^{148}$ Unter dem Namen des Patriarchen Leon Styp(p)es (1134-1143) wurde eine sehr umfangreiche Apo-

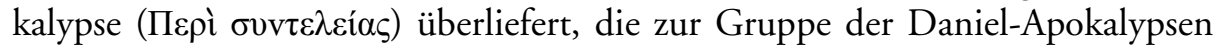
zu zählen ist. ${ }^{149}$ Der Familienname des Patriarchen, der sonst nur spärlich bezeugt ist, deutet auf seine Zugehörigkeit zur Styppeiotes-Familie, die seit dem 9. Jh. nachweisbar ist. Eine Generation vor Michael hätte also ein prominentes Mitglied seiner Sippe Verbindungen, welcher konkreten Art auch immer, zur Apokalyptik gehabt. ${ }^{150}$

Ioannes Kinnamos bezeichnete die Erforschung der Zukunft (den erhofften

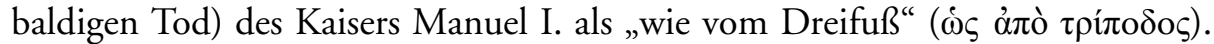
Diese Bezeichnung für divinatorische Tätigkeit, für „Erforschung“ der Zukunft,

schwelgte. Siehe M. Treu, Nicephori Chrysobergae Ad Angelos orationes tres. 127. Programm des Königlichen Friedrichs-Gymnasiums zu Breslau. Breslau 1892, 24-35; eine englische Übersetzung (mit wichtiger Diskussion des Textes) bei Ch.M. Brand, A Byzantine Plan for the Fourth Crusade, Spec. 43 (1968) 462-475, hier 465-472.

146 Ediert von Schmoldt, Die Schrift (wie Anm. 31), 202-218 und Vassiliev, Anecdota (wie Anm. 31), 38-43 (CAVT 257; BHG 1875); zur Datierung siehe u.a. Alexander, Apocalyptic Tradition (wie Anm. 27), 77-92; Pertusi, Fine di Bisanzio (wie Anm. 27), 41, 44 f.; Möhring, Der Weltkaiser der Endzeit (wie Anm. 54), 311 (2. H. 9. Jh.); Brandes, Apokalyptische Literatur (wie Anm. 27), 316 f.; Ders., Endzeitvorstellungen und Lebenstrost (wie Anm. 121), 28 f. Obwohl der Text zweifellos Material enthält, das auf das 9. Jh. weist, sind Zweifel an einer Abfassungszeit in diesem Jahrhundert angebracht.

147 Schmoldt, Die Schrift (wie Anm. 31), 202 (cap. 1).

148 Kresten, JÖB 27 (1978) 83; Kazhdan, ODB 1972.

149 R. Maisano, Lapocalisse apocrifa di Leone di Constantinopoli (Nobilità dello spirito n.s., 3). Napoli 1975 (BHG 1871a); vgl. P. Speck, Konstantin VI, II. München 1978, 812 f. (Anm. 421); Brandes, Apokalyptische Literatur (wie Anm. 27), 318 f. Da im Text Azymen eine Rolle spielen, ist eine Datierung des überlieferten Textes ins 9. Jh., wie meist vermutet wurde, eher unwahrscheinlich. Das schließt nicht aus, daß dieser Text zahlreiche Elemente enthält, die aus dem 8. oder 9. Jh. stammen. Vielleicht gehen diese aber in erster Linie auf die Benutzung der Chronographia des Theophanes zurück.

150 Dabei ist es gleichgültig, ob der Patriarch Leon tatsächlich der Autor der von Maisano edierten Apokalypse ist. Schon der Umstand, daß man ihm eine solche zuschrieb, deutet - ganz allgemein gesagt - auf eine Verbindung zur apokalyptischen Literatur. 
geht auf den Neoplatonismus des 6. Jhs. ${ }^{151}$ insbesondere auf Ioannes Philoponos, zurück, ${ }^{152}$ den großen neoplatonischen Philosophen aus Alexandria. ${ }^{153}$ Es ist erstaunlich und überraschend, aber diese Formulierung „wie vom Dreifuß" findet sich - abgesehen von Philoponos im 6. Jh. - nur noch bei einem Zeitgenossen des Ioannes Kinnamos wieder, der ebenfalls Historiker war, bei Niketas Choniates. ${ }^{154}$ Zwar erlebte die neuplatonische Literatur seit der sog. Makedonischen Renaissance im 9. und 10. Jh. eine große Beachtung (man denke nur an Leon Mathematikos, Arethas oder Photios), ${ }^{155}$ doch findet sich eine ähnliche Formulierung erst wieder bei Niketas Choniates.

Als sich im September 1189 Friedrich Barbarossa mit seinem Kreuzfahrerheer Konstantinopel näherte und man - tatsächlich nicht unbegründet ${ }^{156}$ damit rechnen mußte, daß er Konstantinopel angreifen würde, „weissagte“ der

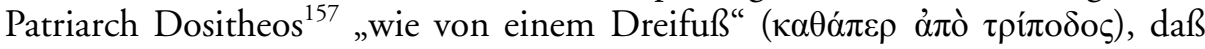

151 G. Dagron, Constantinople imaginaire. Études sur le recueil des Patria (Bibliothèque byzantine, études 8). Paris 1984, 107-125, 132 mit Anm. 25. Zu einem „Dreifuß der Hekate", aufbewahrt im Praetorium in Konstantinopel, siehe Georgius Cedrenus Ioannis Scylitzae, ed. I. Becker, I. Bonn 1838, 563. Zu derartigen Geräten, gefunden bei Ausgrabungen in Pergamon und Apameia (Ende 3. bzw. 6. [?] Jh.), siehe zuletzt A. Mastrocinque, The Divinatory Kit from Pergamon and Greek Magic in Late Antiquity, Journal of Roman Archaeology 15 (2002) 173-188 sowie R. Gordon, Another View of the Pergamon Divination Kit, ebenda, 189-198.

152 Siehe zu ihm B. Baldwin/A.-M. Talbot, ODB 1657 und die dort notierte Literatur.

153 Philoponi (olim Ammonii) in Aristotelis categorias commentarium, ed. A. Busse (Commentaria in Aristotelem Graeca, XIII/1). Berlin 1898 (Nachdruck 1999), 6,32; Ioannes Philoponus, De aeternitate mundi contra Proclum, ed. H. Rabe. Leipzig 1899, 318,2 .

154 Siehe auch Cinnami Etheopoieia, ed. G. Bánhegyi (Magyar-Görög Tanulmányok, 23). Budapest 1943, 10 (1. 66) - bezogen auf die pythischen Orakel. Selbstverständlich spielte der „Dreifuß“ seit den Zeiten der Pythia eine zentrale Rolle im Orakelwesen.

155 P. Lemerle, Le premier humanisme byzantin (Bibliothèque byzantine, études 6). Paris $1971,171-280$.

156 E. Eickhoff, Friedrich Barbarossa im Orient (IM, Beiheft 17). Tübingen 1977, 68-74; siehe auch Der Kreuzzug Friedrich Barbarossas 1187-1190. Bericht eines Augenzeugen. Eingeleitet, übersetzt und kommentiert von A. Bühler (Fremde Kulturen in alten Berichten, 13). Stuttgart 2002, 27 (mit den Verweisen).

157 Dieser hatte sich Isaak II. bereits durch frühere Weissagungen empfohlen, da er ihm sein Kaisertum vorausgesagt hatte. Daß Isaaks Denken stark von eschatologischen Vorstellungen geprägt war - auch seine eigene Rolle betreffend - , hat zuletzt P. Magdalino, Isaac II, Saladin and Venice (demnächst in: The Expansion of the Orthodox World, ed. J. Shepard. Aldershot [im Druck]) gezeigt. Ich danke Paul Magdalino auch an dieser Stelle herzlich für die Überlassung des ungedruckten Manuskripts. Isaak machte Dositheos zuerst zum (in Konstantinopel residierenden) Patriarchen von Jerusalem. Dann installierte er ihn zeitweise als Patriarchen von Konstantinopel. Möglicherweise entstand aus diesem Anlaß die Schrift Пєрì $\mu \varepsilon \tau \alpha \theta \varepsilon \dot{\sigma \varepsilon} \omega v$ (Rhalles/Potles, Syntagma [wie Anm. 13] V, 391-394 = PG 119, 904-909; J. Darrouzès, Le traité des transferts. Édition critique et commentaire, REB 42 [1984] 147-214 [Text: 171-189]; vgl. Beck, Kirche und 
die Franken durch das Xylokerkos-Tor (das heutige Belgrat kap1) ${ }^{158}$ in die Stadt eindringen und viele Untaten begehen würden. Dann allerdings werde Gottes Rache sie treffen und sie geschlagen werden. ${ }^{159}$ Kaiser Isaak II. reagierte völlig logisch im Kontext seines Denkens und des Erfahrungs- und Denkhorizonts seiner Zeit. ${ }^{160} \mathrm{Da}$ er das Heer des 3. Kreuzzugs in offener Feldschlacht nicht vernichten konnte, dazu war das Heer Friedrich Barbarossas zu kampfstark, wie sich bei mehreren Gelegenheiten deutlich gezeigt hatte, verlegte er ihm den Weg des offenbar als sicher erwarteten Angriffs auf die Hauptstadt: Er ließ das Xylokerkos-Tor vermauern. Erst 1346 wurde es wieder geöffnet. ${ }^{161}$ Bald jedoch, jedenfalls lange vor 1453, wurde es wieder verbarrikadiert, und in diesem $\mathrm{Zu}$ stand blieb es bis 1886. Auch die Osmanen kannten die byzantinischen Vaticinien. ${ }^{162}$

So jedenfalls berichtet es Niketas Choniates, Zeitgenosse, hoher Staatsbeamter, Augenzeuge, aufmerksamer Beobachter und Berichterstatter. ${ }^{163}$ Diese Weissagung sei, so Niketas, auch die Ursache dafür gewesen, daß Isaak den Friedensbeteuerungen Friedrich Barbarossas keinen Glauben schenkte. Entsprechend befahl er Angriffe gegen die Kreuzfahrer und verbündete sich wahrscheinlich sogar mit Saladin, dem Erzfeind der Lateiner. ${ }^{164}$

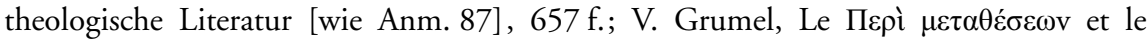
patriarche de Constantinople Dosithée, [R]EB 1 [1943] 239-249), die eine wichtige Rolle in der kanonistischen Literatur der folgenden Jahrhunderte spielte. Vgl. noch M. Angold, Church and Society in Byzantium under the Comneni, 1081-1261. Cambridge 1995, 122 f.; V. Grumel, DHGE 14 (1960) 699; Ch.M. Brand, Byzantium Confronts the West, 1180-1204. Cambridge/Mass. 1968, 100 f., 342 Anm. 63.

158 Siehe zu diesem Tor R. Janin, Constantinople byzantine. Paris 1964, 274 f.; MüllerWiener, Bildlexikon (wie Anm. 37), 287, 293, 295; Berger, Untersuchungen zu den Patria Konstantinupoleos (wie Anm. 36), $621 \mathrm{f}$.

159 Text in Anm. 164.

160 Lilie, Byzanz und die Kreuzzüge (wie Anm. 138), 138 verweist allein auf den „Aberglauben" Isaaks II.

161 Ioannis Cantacuzeni Historiarum libri IV, ed. L. Schopen, II. Bonn 1830, 558.

162 Siehe z. B. St. Yerasimos, La fondation de Constantinople et de Sainte-Sophie dans les traditions turques. Légendes de l'empire (Bibliothèque de l'Institut Française d'Études Anatoliennes d'Istanbul, 31). Paris 1990.

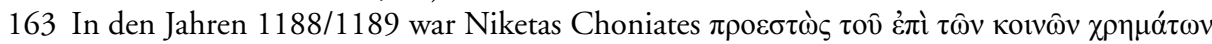

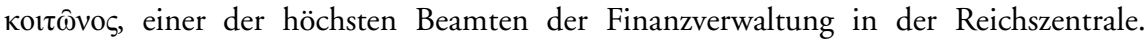
Vorher oder gleichzeitig war er "Sekretär“ des Kaisers Isaak II. Zum Zeitpunkt des Einmarschs des Heeres Friedrich Barbarossas ins Byzantinische Reich kommandierte er in Philippopolis (Plovdiv), war also unmittelbar selbst in die von ihm beschriebenen

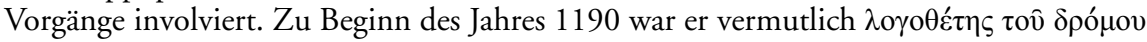

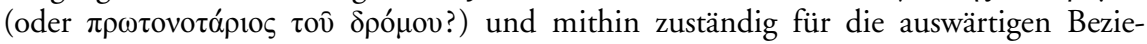
hungen. Siehe J.-L. van Dieten, Niketas Choniates. Erläuterungen zu den Reden und Briefen nebst einer Biographie (Supplementa Byzantina, 2). Berlin/New York 1971, 27 33.

164 Zum Verhältnis Isaaks II. zu Friedrich Barbarossa siehe Eickhoff, Friedrich Barbarossa im Orient (wie Anm. 156), 61-77; M. Bachmann, Die Rede des Johannes Syropulos an 
Es ist bisher nicht bemerkt worden, ${ }^{165}$ daß es sich bei der Schließung des Xylokerkos-Tores durch Isaak II. nicht einfach um eine Erscheinungsform „finstersten Aberglaubens" handelte, den es natürlich auch im 12. Jh. (wie zu allen Zeiten) gab. ${ }^{166}$

Beschäftigt man sich ernsthaft mit der mittelalterlichen apokalyptischen Literatur - egal ob im griechischen Osten oder im lateinischen Westen ${ }^{167}$-, so

den Kaiser Isaak II. Angelos (1185-1195). Inaug.-Diss. München 1935, bes. 65-67; K. Zimmert, Der deutsch-byzantinische Konflikt von Juli 1189 bis Februar 1190, BZ 12 (1903) 43-77; zum eventuellen Bündnis mit Saladin siehe demnächst Magdalino, Isaac II, Saladin and Venice (wie Anm. 157); Angold, The Fourth Crusade (wie Anm. 63), 64 ff. und H. Möhring, Saladin und der dritte Kreuzzug (Frankfurter Historische Abhandlungen, 21). Wiesbaden 1980, 177 ff.; Ch.M. Brand, The Byzantines and Saladin, 1185-1192: Opponents of the Third Crusade, Spec. 37 (1962) 167-181; Nik. Chon.

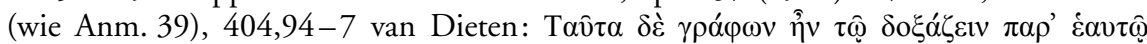

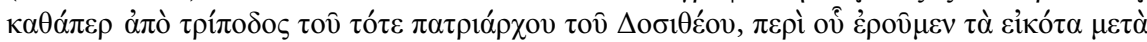

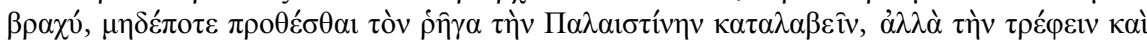

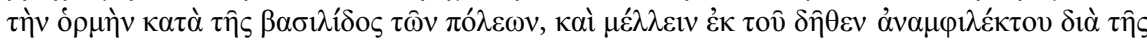

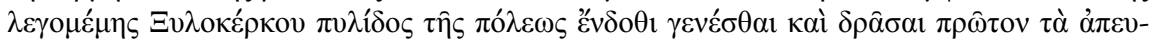

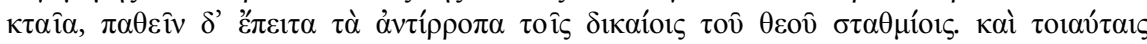

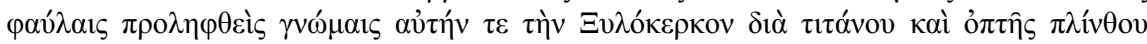
$\dot{\alpha} \pi \varepsilon \dot{\varphi} \varphi \rho \alpha \xi \varepsilon$... Vgl. O City of Byzantium, Annals of Niketas Choniatēs, transl. by H.J. Magoulias. Detroit 1984, 222; Abenteurer auf dem Kaiserthron. Die Regierungszeit der Kaiser Alexios II., Andronikos und Isaak Angelos (1180-1195) aus dem Geschichtswerk des Niketas Choniates übersetzt ... von F. Grabler (Byzantinische Geschichtsschreiber, 8). Graz/Wien/Köln 1958, 207 f.; Niceta Coniata, Grandezza e catastrofe di Bisanzio (Narrazione cronologica), II, a cura di A. Pontani. s.l. 2001, 428.

165 Siehe jedoch schon Brandes, Die Eroberung Konstantinopels im Jahre 1204 (wie Anm. 55) zu diesem bemerkenswerten Vorgang. Inzwischen hat auch P. Magdalino, Prophecies on the Fall of Constantinople, in: Urbs capta. The Fourth Crusade and its Consequences, ed. by A. Laiou. Paris 2005, 41-53, hier 51, unabhängig von mir den Zusammenhang erkannt. Ihm sei für die Überlassung seines damals noch ungedruckten Manuskripts gedankt.

166 Man denke nur an die „Aktivitäten“ des Skleros Seth, über die Niketas Choniates berichtet, siehe Nik. Chon. (wie Anm. 39), 147 f., 339 f. van Dieten (dazu C.F. Further/ E.H. McNeal, The Story of Isaac and Andronicus, Spec. 9 [1934] 324-329); vgl. Magdalino, The Empire of Manuel I (wie Anm. 90), 379; siehe allgemein R.P.H. Greenfield, Traditions of Belief in Late Byzantine Demonology. Amsterdam 1988; A. Delatte/Ch. Josserand, Contribution à l'étude de la démonologie byzantine, AIPhO 2 (1934 = Mélanges Bidez) 207-232. Einen bemerkenswerten Text, der aus der Retrospektive diese Vorgänge behandelt (basierend auf Niketas Choniates), edierte J. Müller, Byzantinische Analekten (Sb. der Kaiserl. AdW Wien, phil.-hist. Kl., Abh. 9). Wien 1852, 336-365; dazu siehe C. Matzukis, Oracles, Visions and Divine Intervention (in

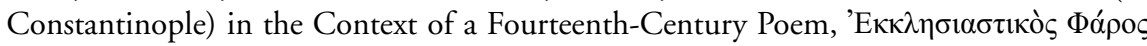
68/69 (1986/1987) 5-21.

167 Wobei die Skepsis unter Mediävisten größer zu sein scheint als unter Byzantinisten. Vgl. zuletzt R. Schieffer, Neues von der Kaiserkrönung Karls des Großen (Sb. der Bayer. AdW, phil.-hist. Kl., Jg. 2004, H. 2). München 2004, 20-24, der, bei aller Ausgewogenheit der Darstellung, seine Bedenken nicht verhehlen kann. Ihm folgte zuletzt M. 
wird man schnell mit der Frage nach der Relevanz derartiger Forschungen konfrontiert. Eine gewisse Bedeutung für Probleme der Mentalitäts- oder der Geistes- und Kulturgeschichte in einem allgemeinen Sinne wird zwar zugestanden; doch eine Rolle für den Verlauf der "großen Politik“, für bestimmte Motive des Handelns historisch wichtiger Persönlichkeiten anzunehmen, stößt in der Regel auf Ablehnung oder Unverständnis. Doch im Falle des Kaisers Isaak II. Angelos, der sich offenbar sogar als den in der Apokalyptik so bedeutenden Endzeitkaiser begriff, wie Paul Magdalino kürzlich zeigte, ${ }^{168}$ ist eine Beeinflussung seines politischen Handelns durch apokalyptische Vorstellungen mit Händen zu greifen. Das betrifft nicht nur die Vermauerung eines Tores der byzantinischen Hauptstadt, durch das der feindliche Angriff erwartet wurde, sondern - wie eben ausgeführt - auch wesentliche Aspekte seiner Außenpolitik.

Die Weissagung des Patriarchen Dositheos und die Reaktion des Kaisers Isaak II. Angelos darauf sind nichts anderes als die Projektion einer fast 500 Jahre alten apokalyptischen Untergangsprophetie auf ihre konkrete Gegenwart im Jahre 1189. Während der letzten großen Belagerung Konstantinopels durch die muslimischen Araber in den Jahren 717/718 entstand ein endzeitlich geprägter Text, ${ }^{169}$ der die unmittelbar bevorstehende Eroberung Konstantinopels voraussagte. „Ismael“ (hier: die muslimischen Araber) werde durch eben das Xylokerkos-Tor in die Stadt eindringen. Erst am bous würden sie durch

Becher, Mantik und Prophetie in der Historiographie des frühen Mittelalters. Überlegungen zur Merowinger- und frühen Karolingerzeit, in: Mantik. Profile prognostischen Wissens in Wissenschaft und Kultur, hg. von W. Hogrebe. Würzburg 2005, 167-187.

168 Siehe Magdalino, Isaac II, Saladin and Venice (wie Anm. 157). Schon allein der Umstand, daß Isaak II. davon ausging, er würde 32 Jahre regieren (Nik. Chon. [wie Anm. 39], 419,8 van Dieten), also genau die Regierungsdauer, die die byzantinische Apokalyptik in der Regel dem Endzeitkaiser zubilligt (siehe schon oben Anm. 106), spricht für Magdalinos (mit weiteren Argumenten und Quellenstellen abgesicherte) Meinung. Siehe schon Mango, ZRVI 6 (1960) 64.

169 Dazu ausführlich W. Brandes, Die Belagerung Konstantinopels 717/718 als apokalyptisches Ereignis. $\mathrm{Zu}$ einer Interpolation im griechischen Text der Pseudo-MethodiosApokalypse, in: Byzantina Mediterranea. Festschrift für Johannes Koder zum 65. Geburtstag, hg. von K. Belke/E. Kislinger/A. Külzer/M.A. Stassinopoulou. Wien 2007, 6591. Siehe schon Dens., Ephesos in byzantinischer Zeit, Klio 64 (1982) 611-622, hier 619; Ders., Apokalyptisches in Pergamon, Bsl. 48 (1987) 1-11, hier 8; Ders., Apo-

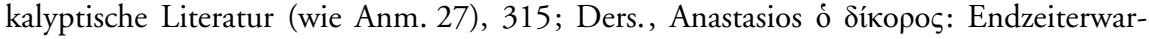
tung und Kaiserkritik in Byzanz um 500 n. Chr., 90 (1997) 24-63, hier 52 mit Anm. 195 und 196; Ders., Byzantine Cities in the Seventh and Eighth Centuries Different Sources, Different Histories? in: The Idea and Ideal of the Town between Late Antiquity and the Early Middle Ages, ed. by G.P. Brogiolo/B. Ward-Perkins (Transformation of the Roman World, 4). Leiden/Boston/Köln 1999, 25-57, hier 49-53; siehe auch W.J. Aerts, Zu einer neuen Ausgabe der „Revelationes“ des Pseudo-Methodius (Syrisch-Griechisch-Lateinisch), in: XXIV. Deutscher Orientalistentag, vom 26. bis 30. September 1988 in Köln. Ausgewählte Vorträge, hg. von W. Diem und A. Falaturi (ZDMG, Suppl. 7). Stuttgart 1990, 123-130. 
Gottes Eingreifen gestoppt und aus der Stadt unter großen Verlusten vertrieben werden. ${ }^{170}$ Dieser kurze Text wurde später in die 1. griechische Redaktion der Apokalypse des Pseudo-Methodios interpoliert und fand so, als Bestandteil der wichtigsten apokalyptischen Schrift, eine größere Verbreitung. Dositheos ersetzte "Ismael“ einfach durch Alemannoi und konnte so deren negativen Charakter und ihre üblen Absichten „beweisen“.

Zurück ins Jahr 1159 und zur Affäre des Theodoros Styppeiotes, die übrigens mit Blendung, Abschneiden der Zunge und langjähriger Inhaftierung endete. Etwa zur selben Zeit wurde auch ein Verfahren gegen Michael Glykas, der als Autor und Historiker bekannt ist, ${ }^{171}$ eröffnet. Er hatte einen subalternen Posten (grammatikos) in der kaiserlichen Kanzlei inne und war entsprechend ein Untergebener der Theodoros Styppeiotes. Einen Zusammenhang zwischen den Gerichtsverfahren der beiden hat Kresten bewiesen. ${ }^{172}$ Glykas war wohl als "Mitläufer" in die Verschwörung verwickelt bzw. wurde als ein solcher behandelt. Sein Verfahren, das mit "leichter Blendung“ endete, soll hier allein deshalb erwähnt werden, weil Michael Glykas wegen Zauberei und Magie angeklagt und verurteilt wurde. Es ist nicht auszuschließen, daß sich hinter diesem Vorwurf ebenfalls die „kaiserfeindliche“ Benutzung apokalyptischer Schriften bzw. von Kaiserorakeln verbirgt. Michael Glykas ist immerhin der einzige byzantinische Historiker (und einer der ganz wenigen Autoren der tausendjährigen byzantinischen Literaturgeschichte), der in seinem Geschichtswerk ausdrücklich eine der nach dem 7. Jh. entstandenen byzantinischen Apokalypsen zitiert, nämlich die des Pseudo-Methodios. ${ }^{173}$

Bereits vor Jahrzehnten machte Cyril Mango auf den Umstand aufmerksam, daß sich seit dem ausgehenden 11. Jh. eine bemerkenswerte Verbindung zwi-

170 Die Apokalypse des Pseudo-Methodius. Die ältesten griechischen und lateinischen Übersetzungen, I, hg. von W.J. Aerts/G.A.A. Kortekaas (CSCO 569; Subisdia 97).

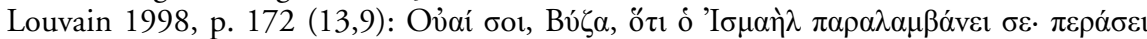

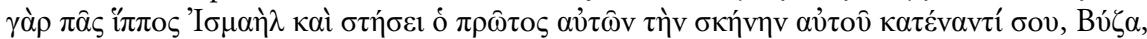

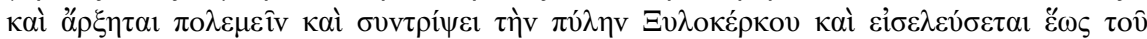

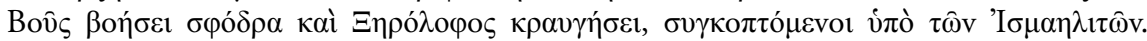
Vgl. auch den 2. Band mit den Kommentaren (CSCO 570; Subsidia 98). Louvain 1998, 49 f. (allerdings sehr defizitär); der Text auch bei Schmoldt, Die Schrift (wie Anm. 31), 282. Siehe jetzt besonders A. Berger in diesem Band (S. 135-155).

171 Siehe zu ihm P. Schreiner, LexMa IV (1993) 1519 (mit Literatur; zu ergänzen ist Kresten [wie in Anm. 139]).

172 Kresten, JÖB 27 (1978) bes. 66-73, 90-95.

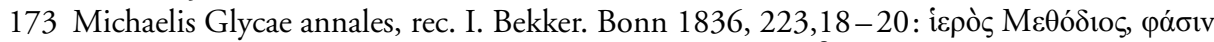

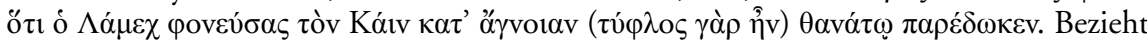
sich auf Pseudo-Methodios [2] 1,4 (76 Aerts [wie Anm. 170]); Glykas spricht sich übrigens gegen die zitierte Ansicht des Pseudo-Methodios aus. Die Stelle beweist jedenfalls, daß Michael Glykas die Apokalypse des Pseudo-Methodios kannte und es sogar wagte, sie zu zitieren (allerdings an einer „unverfänglichen“ Stelle). 
schen Leon dem Weisen (und seinen „Orakeln“) und dem Propheten Daniel feststellen läßt. ${ }^{174}$ Um das Jahr 1200 herum besuchte der russische Pilger Antonij (als Laie Dobrynja Jadrejkovič; später u.a. Erzbischof von Nowgorod) Konstantinopel. ${ }^{175}$ In dem Bericht über seine Wallfahrt zu den zahlreichen verehrungswürdigen Reliquien in Konstantinopel (Kniga palomnik) teilt er mit, daß Leon der Weise aus der Grabstätte des heiligen Propheten Daniel in „Babylon" eine Schrift genommen und diese abgeschrieben habe. Die Schrift aber enthielt Nachrichten über die zukünftigen Kaiser Konstantinopels, solange die Stadt noch bestehen werde. ${ }^{176}$ Dies zeigt, so schon Mango, daß um 1200 bereits Weissagungen Leons bekannt waren. Interessanterweise wurden diese aber auf den Propheten Daniel zurückgeführt!

Die Reliquien des Propheten Daniel als Objekte der Verehrung tauchen vereinzelt seit dem ausgehenden 10. Jh. in den Quellen auf. ${ }^{177}$ Nach den Patria hat sie Helena, die Mutter Konstantins des Großen, nach Konstantinopel gebracht. ${ }^{178}$ In einer Krypta der Romanoskirche befanden sich die Sarkophage Daniels und der drei Jünglinge, wie verschiedenen Pilgerberichten zu entnehmen ist. ${ }^{179}$

174 Mango, ZRVI 6 (1960) $71 \mathrm{f}$.

175 S. Franklin/A. Cutler, ODB 124; Podskalsky, Christentum und theologische Literatur in der Kiever Rus' (wie Anm. 82), 200 f.

176 Itineraria Rossica. Altrussische Reiseliteratur, hg. und übers. von K. Müller. Leipzig 1986, 105: „Jener Kaiser, der Herrscher Leon, nahm die Urkunde in der Grabstätte des heiligen Propheten Daniel und schrieb sie ab, wie es Philosophen tun; die Urkunde besagt, wer in Zargrad Kaiser sei, solange es besteht." Siehe auch die französische Übersetzung von M. Ehrhard, Le livre du pèlerin d'Antoine de Novgorod, Romania 58 (1932) 44-65, hier 51 f. zu Leon dem Weisen, der in Babylon im Grab des Propheten Daniel ein Manuskript gefunden habe; es wurde später ins Griechische übersetzt: „on y trouve inscrits les noms des tsars grecs et de tous ceux qui doivent être tsars tant qu'existera Tsargrad“. In einer anderen Hs. : „..., ayant pris un manuscrit dans le tombeau du saint prophète Daniel, le transcrivit avec sagesse et annonça qui serait tsar à Tsargrad aussi longtemps que Tsargrad subsisterait. “

177 Daniel wurde am 17. Dezember verehrt. Siehe Synaxarium ecclesiae Constantinopolitanae, ed. H. Delehaye (Propylaeum ad AASS Novembr.). Bruxelles 1902, 317,16-320,8.

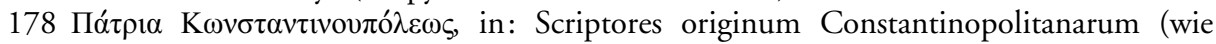
Anm. 36), 245,3-12 (III.81) Preger; dazu Berger, Patria (wie Anm. 158), 667-669.

179 G.P. Majeska, A Medaillon of the Prophet Daniel in the Dumbarton Oaks Collection, DOP 28 (1974) 361-366, hier 363 mit Anm. 12; Ders., Russian Travellers to Constantinople in the Fourteenth and Fifteenth Centuries (DOS 19). Washington D.C. 1984, 326-329; J. Ebersolt, Sanctuaires de Byzance. Recherches sur les anciens trésors des églises de Constantinople. Paris 1921, 108 f.; Manuelis Philae carmina, ed. E. Miller, I. Paris 1855, 51 Nr. 108; siehe auch K.N. Ciggaar, Une description de Constantinople traduite par un pèlerin anglais, REB 34 (1976) 211-267, hier S. 262 (\$59). 
Die behandelten drei historischen Vorgänge, in der ersten Hälfte des 9., in der Mitte des 12. und am Ende des 13. Jhs., die alle als hochverräterische Aktionen gegen den jeweils regierenden Kaiser erscheinen, haben eine Gemeinsamkeit: Es wurden apokalyptische Schriften bzw. Kaiserorakel, die mit diesen sehr eng verwandt sind, benutzt, um die politische Position des angegriffenen Kaisers zu unterminieren. Die Kaiser reagierten stets überaus heftig, und Verstümmelungen oder Todesstrafen waren die Folge.

Kaiser wie Opponenten, das wird deutlich, glaubten gleichermaßen an die Relevanz derartiger Schriften. Beide Seiten sahen in ihnen göttliche Offenbarungen, den Menschen vermittelt durch heilige Männer, an deren Wahrheitsgehalt nicht gezweifelt wurde. Das Verfassen, Verbreiten und der Besitz dieser Schriften war seit der Spätantike nach geltendem Recht verboten. Die angedrohten Strafen waren gravierend.

Das eigenartige Phänomen, daß die byzantinische apokalyptische Literatur auf der einen Seite durch zahlreiche (meist sehr späte) Handschriften überliefert wurde und daß auf der anderen Seite es fast keine direkten Hinweise auf sie in der sonstigen Literatur gibt (indirekte gibt es einige), kann vielleicht durch diese rechtliche Situation erklärt werden. Wer wollte sich schon in den Dunstkreis eines eventuellen Hochverrats begeben? Das taten „Überzeugungstäter“ wie Methodios und sein Anhang in der ersten Häfte des 9. Jhs. und Personen, die ernsthaft auf einen Umsturz hinarbeiteten, oder Menschen, die an ihrer Gegenwart (am regierenden Kaiser) verzweifelten und auf eine Besserung der als unerträglich empfundenen Gegenwart in der Zukunft hofften.

Offenbar war man sich staatlicherseits und - auf der anderen Seite - im Kreis der byzantinischen Literaten, die meist vom Hof und dessen Wohltaten abhängig waren, stets der potentiellen Gefährlichkeit der Apokalypsen und Orakel bewußt und vermied es, durch ihre Verbreitung oder ausführliche Benutzung im eigenen literarischen Schaffen in den Verdacht zu geraten, mit ihrer Hilfe den Kaiser zu kritisieren und sich mithin der Gefahr der Verfolgung oder doch wenigstens des Gunstentzuges auszusetzen.

Vielleicht läßt sich auch so (u.a.) das auffällige Phänomen erklären, daß ca. $80-90 \%$ aller Handschriften (eine grobe Schätzung), die derartige Texte überliefern, aus der Zeit nach 1453 stammen. Nachdem der byzantinische Staat und sein Kaiser verschwunden waren, konnte man auch nicht mehr des Hochverrats gegen diese verdächtigt werden. ${ }^{180}$

180 Dies ist natürlich nur eine Hypothese. Daß nach 1453 die Produktion von Handschriften mit apokalyptischen Texten und Orakeln etc. enorm zunahm, hing sicher auch mit dem für das Jahr 1492 n. Chr. (7000 der byzantinischen Ära) erwarteten Weltende zusammen. In diesem Zusammenhang suchte man die Erklärung des Untergangs des 
Diese schlechte Überlieferungslage macht es notwendig, die existente und viel zu wenig beachtete lateinische Übersetzungsliteratur in die byzantinistische Forschung einzubeziehen, zumal diese westlichen Texte wesentlich besser überliefert sind als ihre griechischen Vorlagen.

Derartige Forschungen könnten sich auch stimulierend auf die lateinische Mediävistik auswirken. Die Rezeption byzantinischer Schriften apokalyptischen Charakters erfolgte ja nicht zufällig im 13. Jh., beginnend im 12. Jh., in einer Zeit, in der ja auch der Westen eine in apokalyptischen Formulierungen und Begriffen schwelgende Publizistik kannte ${ }^{181}$ und die Schriften eines Joachim von Fiore ihre Wirkung entfalteten. Dieses transkulturelle Phänomen verdient eine intensivere Beschäftigung als bisher geschehen. Seine Erforschung könnte dazu beitragen, zu einem besseren Verständnis der Formierung des historischen Europa beizutragen. Dieses nahm mehr Elemente aus dem griechischen Osten auf, als man gemeinhin annimmt. ${ }^{182}$ Die hier behandelten Vorgänge zeigen, daß eine

Byzantinischen Reiches auch im Kontext der universaleschatologischen Vorstellungen. Siehe dazu zuletzt Brandes, Der Fall Konstantinopels 1453 als apokalyptisches Ereignis (wie Anm. 66). Die um das Jahr 1000 a.D. auch in Byzanz bemerkbare gesteigerte Endzeiterwartung ist inzwischen durch eine erstaunlich große Anzahl eindeutiger Textzeugnisse belegt (siehe W. Brandes, Liudprand von Cremona (Legatio cap. 39-41) und eine bisher unbeachtete west-östliche Korrespondenz über die Bedeutung des Jahres 1000 a.D., BZ 93 [2000] 435-463; P. Magdalino, Une prophétie inédite des environs de l'an 965 attribué à Léon le Philosophe [Ms Karakallou 14, f. $253^{\mathrm{r}}-254^{\mathrm{r}}$ ], TM 14 [2002] 391-402; Ders., The Year 1000 in Byzantium, in: Byzantium in the Year 1000, ed. by P. Magdalino [The Medieval Mediterranean, 45]. Leiden/Boston 2003, 233270; I. Ševčenko, Unpublished Byzantine Texts on the End of the World about the Year 1000 AD, TM 14 [2002] 561-578), doch spiegelt sich dies nicht (was natürlich angesichts der bekannten Überlieferungsbedingungen griechischer Handschriften zu erwarten ist) im bekannten Handschriftenbestand wider.

181 Siehe u. a. H.M. Schaller, Endzeit-Erwartung und Antichrist-Vorstellungen in der Politik des 13. Jahrhunderts, in: Ders., Stauferzeit. Ausgewählte Aufsätze (MGH - Schriften, 38). Hannover 1993, 25-52 (ursprgl. 1972); M. Reeves, The Influence of Prophecy in the Later Middle Ages. A Study in Joachimism. Notre Dame/London ${ }^{2} 1993$.

182 Es wurde festgestellt, daß gerade im 11. und 12. Jh., als in Byzanz wie in Westeuropa ein allgemeiner geistiger Aufbruch registriert werden kann, Kontakte auf einer intellektuell anspruchsvolleren Ebene kaum zu finden sind. Siehe R. Browning, Enlightment and Repression in Byzantium in the Eleventh and Twelfth Centuries, Past and Present 69 (1975) 3-23, hier bes. 19 f. Siehe bes. Ch.H. Haskins, The Renaissance of the $12^{\text {th }}$ Century. Cambridge 1927. Zur Sicht Joachims von Fiore und seiner Anhänger auf die Griechen siehe B.E. Whalen, Joachim von Fiore and the Division of Christendom, Viator 34 (2003) 89-108; A.-D. van den Brincken, Die «Nationes Orientalium` im Verständnis der lateinischen Historiographie. Köln 1973, 32-34; H. de Lubac, La postérité spirituelle de Joachim de Fiore. Paris 1978, 36-38. Auf der anderen Seite deutet das verstärkte Auftauchen byzantinischer Motive in dieser Zeit in den gansons de geste und in der volkssprachigen Dichtung Westeuropas im 12. und 13. Jh. auf umfangreiche Kontakte, die sich eben nicht in der "gelehrten Literatur" widerspiegeln. Siehe 
scheuklappenartig verengte Sicht auf Byzanz der byzantinistischen Forschung nicht weiterhilft. Ihre Untersuchung vermag vielleicht auch die Forschung zu befruchten, die sich mit Texten befassen muß, deren Ursprung im Osten liegt. Eine Klärung der Rezeption dieses Gedankengutes sowie der konkreten Rezeptionsbedingungen kann zu bemerkenswerten Einsichten führen. Die Erforschung dieser spezifischen Form des Wissenstransfers steht noch in ihren Anfängen.

I. Seidel, Byzanz im Spiegel der literarischen Entwicklung Frankreichs im 12. Jahrhundert. Frankfurt usw. 1977, 57 ff. 